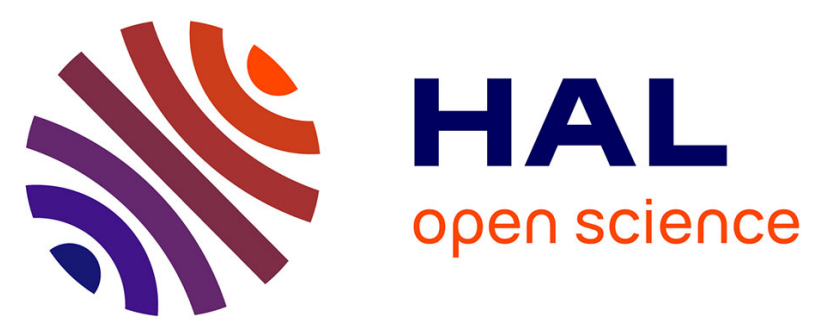

\title{
Fast nanostructured carbon microparticle synthesis by one-step high-flux plasma processing
}

Damien Aussems, Kirill Bystrov, I. Dogan, Cécile Arnas, Martiane Cabié, Thomas Neisius, M. Rasinski, E. Zoethout, P. J.L. Lipman, M. C. M. van de Sanden, et al.

\section{To cite this version:}

Damien Aussems, Kirill Bystrov, I. Dogan, Cécile Arnas, Martiane Cabié, et al.. Fast nanostructured carbon microparticle synthesis by one-step high-flux plasma processing. Carbon, 2017, 124, pp.403 414. 10.1016/j.carbon.2017.08.071 . hal-01585960

\section{HAL Id: hal-01585960 https://hal.science/hal-01585960}

Submitted on 12 Sep 2017

HAL is a multi-disciplinary open access archive for the deposit and dissemination of scientific research documents, whether they are published or not. The documents may come from teaching and research institutions in France or abroad, or from public or private research centers.
L'archive ouverte pluridisciplinaire HAL, est destinée au dépôt et à la diffusion de documents scientifiques de niveau recherche, publiés ou non, émanant des établissements d'enseignement et de recherche français ou étrangers, des laboratoires publics ou privés. 


\title{
Fast nanostructured carbon microparticle synthesis by one-step high-flux plasma processing
}

\author{
D.U.B. Aussems ${ }^{1 *}$, K. Bystrov ${ }^{1}$, I. Dogan ${ }^{1}$, C. Arnas ${ }^{2}$, M. Cabié ${ }^{3}$, T. Neisius ${ }^{3}$, M. Rasinski ${ }^{4}$, \\ E. Zoethout ${ }^{1}$, P. Lipman $^{5}$, M.C.M. van de Sanden ${ }^{1,5}$, T.W. Morgan ${ }^{1}$ \\ ${ }^{1}$ DIFFER - Dutch Institute for Fundamental Energy Research, De Zaale 20, 5612 AJ Eindhoven, \\ the Netherlands
}

${ }^{2}$ CNRS, Aix-Marseille Université, Laboratoire PIIM, Avenue Escadrille Normandie-Niémen 13397, Marseille, France

${ }^{3}$ CP2M, Aix-Marseille Université, Avenue Escadrille Normandie Niemen, 13997 Marseille, France

${ }^{4}$ Forschungszentrum Jülich GmbH, Institut für Energie- und Klimaforschung - Plasmaphysik, Partner of the Trilateral Euregio Cluster (TEC), 52425 Jülich, Germany

${ }^{5}$ Eindhoven University of Technology, PO Box 513, 5600 MB Eindhoven, The Netherlands

\begin{abstract}
This study demonstrates a fast one-step synthesis method for nanostructured carbon microparticles on graphite samples using high-flux plasma exposure. These structures are considered as potential candidates for energy applications such as $\mathrm{Li}$-ion batteries and supercapacitors. The samples were exposed to plasmas in the linear plasma generator Pilot-PSI with an average hydrogen ion-flux of $\sim 10^{24} \mathrm{~m}^{-2} \mathrm{~s}^{-1}$. The parameter window was mapped by varying the ion energy and flux, and surface temperature. The particle growth depended mainly on the sample gross-erosion and the resulting hydrocarbon concentration in the plasma. A minimum concentration was necessary to initiate particle formation. The surface of the sample was covered with microparticles with an average growth rate of $0.2 \mu \mathrm{m} / \mathrm{s}$, which is significantly faster than most chemical methods. The particles were initially volumetrically grown in in the gas-phase by a multiphase process and after deposition on the sample their growth proceeded. Scanning and transmission electron microscopy reveal that the core of these microparticles can be made of an
\end{abstract}

*Corresponding author. E-mail: d.aussems@differ.nl (D.U.B. Aussems) 
agglomeration of nanoparticles, surrounded by crumpled layers of carbon nanowalls. Gas sorption analysis shows sufficient meso- and macropores for fast mass transport. In conclusion, this processing technique could be a novel synthesis route to nanostructure surfaces for electrochemical applications.

\section{INTRODUCTION}

The future demands for renewable energy, electric vehicles, portable electronics and other highpower and high energy density applications require energy storage devices [1]. Electrochemical energy storage has shown a great potential to meet the criteria, but it requires further improvements in the field of high-performance electrode materials [2,3]. Among the potential electrochemical energy storage materials, carbon has several advantages such as good electrical conductivity, stability within a wide range of reactive environment, benign environmental impact, relative low cost, high availability, and easy processability [4]. In particular, improved electrochemical performance can be achieved from porous carbon electrode materials, which exhibits not only a high surface area, but also improved wettability when operated in electrochemical cells [4]. This is due to the existence of sufficient meso- and macropores ( $>2 \mathrm{~nm}$ and $>50 \mathrm{~nm}$, respectively [5]), necessary for a fast accessibility of ions [6,7].

Several chemical processing routes exist for manufacturing porous carbon, which includes activating compact porous materials [8], fabricating aerogels [9], or creating porous carbon by use of hard [10,11] or soft templates [12]. A very promising novel approach is the use of graphene based materials, which has attracted a lot of research attention [7]. This is due to the unique properties of graphene: very high surface area (over $2630 \mathrm{~m}^{2} \mathrm{~g}^{-1}$ ), good mechanical/chemical stability, and high electrical/thermal conductivity [13-15]. Quite recently, nanostructured microparticles, consisting of crumpled graphene oxide, displayed an effective combination of micro and macro structuring and showed good electrochemical performance [16]. However, their formation required a multi-step processing procedure, hindering the efficiency of production.

Alternatively, similarly shaped nanostructured carbon microparticles can be fabricated in plasma environments of the thin-film industry and fusion devices, yet typically undesirably [17-20]. In the thin-film industry these “dust particles” grow during plasma processing and are considered to be contaminants [20]. Dedicated dusty-plasma experiments were hence conducted to gain more insights in their formation mechanisms and transport using low-pressure RF and DC discharges 
[21-28]. Concurrently, similar nano/micro-sized carbon particles have been observed and investigated in fusion research. In these devices the particles are formed due to interaction of the plasma with the graphite tokamak wall and can pose safety hazards in terms of radioactivity and chemical reactivity [29,30]. Experiments on this type of dust formation have been conducted in linear plasma generators [31,32], that can simulate the extreme hydrogen (and isotopes) plasma conditions (ion flux of $\sim 10^{24} \mathrm{~m}^{-2} \mathrm{~s}^{-1}$ ) close to the tokamak walls.

Although initially not intended for this purpose, the use of high-flux plasma exposure in a linear plasma generator has a great potential. First of all, it is a one-step surface modification procedure, i.e., the as-synthesized material is bound to the surface and may hence directly be used in electrochemical cells. In view of this advantage and in contrast to other methods, the active materials does not need to be attached to the surface by an additional binder materials, e.g. polyvinylidene fluoride (PVDF) [16], which will prevent reduction of the electrical resistivity of the electrochemical system [33-36]. Secondly, a reactive hydrogen plasma is the only requirement, i.e., no graphite surface pretreatment or chemical precursor gas injection is needed [31], taking advantage of natural hydrocarbon release. This is in sharp contrast to the chemical synthesis routes, which often require several processing steps and the inevitable use of expensive chemical precursors [8-10,12,16]. Thirdly, the reported carbon microparticle processing rate is very high, up to $0.15 \mu \mathrm{m} / \mathrm{s}$ [31], which results in the full coverage of the sample surface by microparticles within the timeframe of a hundred seconds, which is a critical advantage in terms of the scalability of the process.

Despite the possible advantages, carbon micro/nano-structure synthesis by high-flux plasma exposure is ill-explored and lacks understanding of the particle morphology as well as insights into the growth conditions and mechanisms. This needs to be elucidated in order to use this microparticle processing technique for applications such as electrochemical energy storage. In this study linear plasma generator Pilot-PSI is employed. Although this setup is not optimized for industrial processing, is a convenient setup due to its extensive diagnostic suite and well characterized plasma. Previous work using this machine led to the understanding that the basic requisite of microparticles synthesis is a very high plasma density $\left(>10^{20} \mathrm{~m}^{-3}\right)$ [31]. This extreme condition makes the plasma opaque for hydrocarbon molecules that are released by chemically sputtering from the graphite sample surface, i.e. a large fraction of the sputtered hydrocarbon molecules is redirected back to the surface. This induced recycling of hydrocarbon molecules leads 
to reorganization of the plasma-exposed surface, and eventually to the appearance of microparticles on the surface. Yet, the mechanism that led to nucleation and its conditions remained unclear [31,37] and have not been thoroughly studied in these high density/flux conditions. Moreover, properties of the effective surface area and the pore size distribution, which is important for future applications, are unknown.

In this work we demonstrate a one-step synthesis route for carbon microparticles in the linear plasma generator Pilot PSI with a growth rate of $0.2 \mu \mathrm{m} / \mathrm{s}$. The experimental setup of Pilot-PSI is explained in Sec. 2.1 and the post-processing analysis techniques are explained in Sec. 2.2. The synthesis conditions are explored in terms of graphite surface temperature, incident ion flux and ion energy in Sec. 3.1. The materials related to the conditions are analyzed in detail in Sec. 3.2, while the formation mechanisms are investigated using in-situ diagnostics in Sec. 3.3. Systematic mapping of the growth conditions in combination with the material characterization enabled us to propose a nucleation model in Sec. 4. Finally, the conclusions and outlook are presented in Sec. 5.

\section{EXPERIMENTAL SETUP}

\subsection{Synthesis and in situ diagnostics}

The experimental setup of the linear plasma generator, Pilot-PSI, is depicted in Fig. 1a and is described in more detail in [38,39]. In our experiments, a hydrogen plasma was generated by a cascaded arc plasma source [40] and expanded into a downstream vessel along a magnetic field of 0.4-0.8 T generated by electromagnetic field coils. The radially resolved plasma parameters were measured by a Thomson scattering system [41] $2.7 \mathrm{~cm}$ in front of the sample and show a typically high central electron density $\left(>10^{20} \mathrm{~m}^{-3}\right)$ and an electron temperature of $1-2 \mathrm{eV}$. The plasma parameters were tuned by varying the gas flow and discharge current in the plasma source, and the magnetic field. The plasma beam has a Gaussian shape in the radial direction with a FWHM of 10 mm, which is depicted in Fig. 1b. The plasma flows towards a water cooled, electrically biased sample, fastened with a Mo clamping ring. A typical ion flux $\left(\Gamma_{i} \propto n_{e} \sqrt{T_{e}}\right)$ of $0.5-4 \times 10^{24} \mathrm{~m}^{-2} \mathrm{~s}^{-}$ ${ }^{1}$ was achieved mainly due to the high electron density. Such an ion flux is up to four orders of magnitude higher than in conventional plasma-enhanced chemical vapor deposition processing [31]. The ion energies were in the range of 5-50 eV, and depended on the applied bias voltage (for ion energies below $10 \mathrm{eV}$ a floating sample was used). The sample surface temperature resulting from the subjected heat flux was measured in 2D by using a fast infrared camera (FLIR, SC7500- 
MB) and by a multi-wavelength emissivity-independent pyrometer (FAR Associates, FMPI SpectroPyrometer), pointed at the sample center. A single channel broadband spectrometer (Avantes AvaSpec-2048, wavelength range 378-476) was used to measure the intensity of the optical emission of the $\mathrm{A}^{2} \Delta \rightarrow \mathrm{X}^{2} \Pi(\mathrm{A} \rightarrow \mathrm{X})$ transition (the Gerö band) of the $\mathrm{CH}$ radical at the center of the carbon sample [42]. The emission intensity was integrated from $420.0 \mathrm{~nm}$ to $432.0 \mathrm{~nm}$ and the background signal was subtracted. Additionally, the intensity of the Balmer gamma line $\left(\mathrm{H}_{\gamma}\right)$ of the hydrogen ion at $434.1 \mathrm{~nm}$ was monitored with the same spectrometer. This was used as a qualitative measure of the density of the plasma (assuming $T_{e}$ remains unchanged).
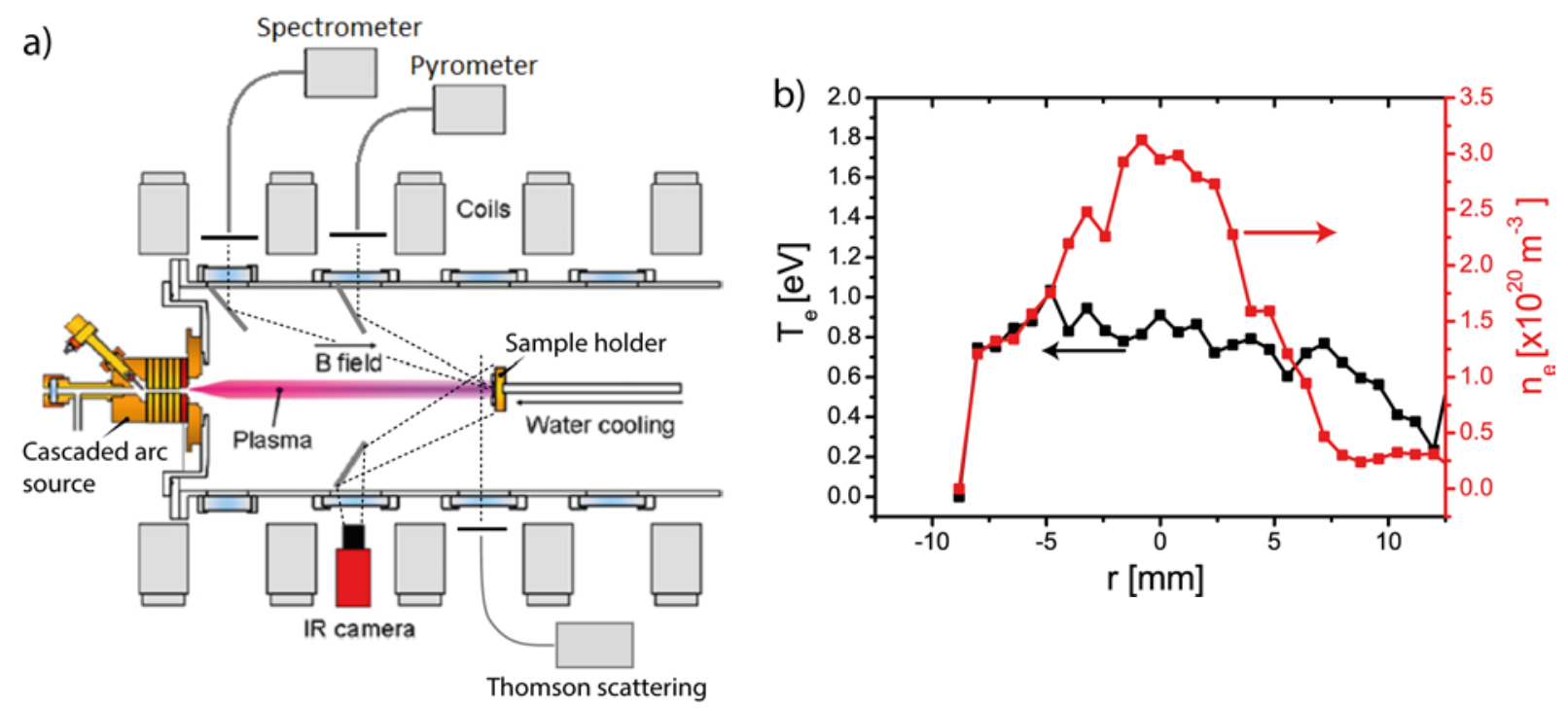

Fig. 1: a) Linear plasma generator Pilot-PSI. The plasma is generated by a cascaded arc source (left), confined by a magnetic field and directed towards a water-cooled sample. Several diagnostics are installed for in-situ plasma characterization and surface analysis. b) Typical plasma conditions show a Gaussian electron density profile and a flat electron temperature profile.

\subsection{Post-processing analysis}

The samples were analyzed post-mortem using several surface analysis techniques. The surface morphology was analyzed using two scanning electron microscope (SEM) devices [Hitach S-4800 and Zeiss Crossbeam 540] operated at electron energies up to $5 \mathrm{keV}$. The latter microscope was also equipped with a focused ion beam source, which was employed to prepare cross-sections of the microparticles, and a backscattered electron detector to trace possible impurity particles. The backscattering electron images (BSE) were taken at an electron energy of $4 \mathrm{keV}$. A confocal 
Raman spectroscopy setup (Renishaw inVia) equipped with a $514 \mathrm{~nm}$ laser, a grating with 1800 lines/mm, and a CCD detector was used to investigate the graphitic crystal structure. An X-ray Photoelectron Spectroscopy (XPS) setup (K-Alpha, Thermo Scientific) with a monochromated Al K $\alpha$ X-ray source (spot size 200-400 $\mu \mathrm{m}$ ) and build-in CCD camera was used to measure the surface contamination level and the type of chemical bondings. The carbon nanoparticles (CNPs) and carbon nanowalls (CNWs) were investigated with a transmission electron microscope (TEM) [FEI Titan 80-300 Cs corrected] that allows for selected area diffraction pattern (SADP) imaging. The impurity content of the particles was analyzed with another TEM [FEI Tecnaï G2] equipped with an energy-dispersive X-ray (EDX) detector [Oxford instruments, SDD XMax 80]. Both TEMs were operated at an acceleration voltage of $200 \mathrm{kV}$. The surface area and pore characteristics of each sample were determined by analyzing their $\mathrm{N}_{2}$ gas sorption isotherms (Micromeritics, TriStar II 3020). The surface area was derived using the Brunauer-Emmett-Teller (BET) method and the pore size distributions from the adsorption branch of the isotherms using the Barrett-Joyner-Halenda (BJH) model.

\section{RESULTS}

\subsection{Synthesis conditions}

The initial surface morphology can play a critical role on the erosion and the formation of surface structures as shown in previous work [33], which can make the interpretation of particle formation complex. For this reason, we used highly oriented pyrolytic graphite (HOPG, NT-MDT Co., 0.81.2 degrees mosaic spread, $1 \mathrm{~mm}$ thickness), which has a significantly lower surface roughness than fine-grain graphite, to minimize this effect. The size of the samples was $12 \times 12 \mathrm{~mm}$, so the total surface area could interact with the plasma beam (10 mm FWHM).

The precursor material and the resulting growth of carbon microparticles depend on the sample gross erosion - the number of etched carbon atoms per incoming hydrogen ion. From previous work done in tokamaks and linear plasma devices under similar conditions, it was found that gross erosion is mainly determined by the surface temperature, and incident ion energy and flux [43]. Therefore, these quantities were varied within various parameter ranges $\left(T_{\mathrm{s} \text {,peak }}=350-1660{ }^{\circ} \mathrm{C}\right.$, $\left.E_{\text {ion }}=3-50 \mathrm{eV}, \Gamma_{\mathrm{i}}=0.9-3.9 \cdot 10^{24} \mathrm{~m}^{-2} \mathrm{~s}^{-1}\right)$. The contribution of recycled neutrals to the erosion could be neglected, because their flux and impact energy is estimated to be a factor 5 and 10 lower, respectively. The HOPG samples were exposed to a hydrogen plasma reaching an ion fluence of 
the order $\sim 10^{26} \mathrm{~m}^{-2}$. These plasma exposures resulted in a variety of nano/microstructures, including microparticles with an unintentional impurity seed (MP-i, further explained in Sec. 3.2), columnar structures consisting of carbon nanowalls (C) and nanostructured spherical microparticles (MP). Table 1 presents the sample exposure conditions and the type of particles formed in the sample center and periphery. The regions are described in Fig. 2. Note that the magnetic field used for the confinement of the plasma was $0.8 \mathrm{~T}$ for all samples, except for samples H1-3, for which $0.4 \mathrm{~T}$ was used.

The gross erosion was diagnosed by optical emission spectroscopy (OES) of the CH radical (i.e. the $\mathrm{CH}$ A-X emission band, Fig. S1 in the supplementary data), which is produced by a sequence of dissociative reactions with etched hydrocarbon molecules [37,42,44-46]. The absolute gross erosion equals the absolute $\mathrm{CH} A-\mathrm{X}$ emission intensity $\phi_{\mathrm{A} \rightarrow \mathrm{X}}^{\mathrm{CH}}$ divided by the photon efficiency of the $\mathrm{CH}$ molecules $\Pi_{\text {phot }}$ (which depends on $n_{\mathrm{e}}$ and $T_{\mathrm{e}}$ ). Although our OES system was not calibrated absolutely, we can account for the $n_{\mathrm{e}} / T_{\mathrm{e}}$ variation of the photon efficiency. The variation with the electron density is caused by collisional de-excitation (or also called collisional quenching) of the $\mathrm{CH}$ molecule, which reduction factor $f_{\text {quench }}$ can be obtained theoretically [42]. The $T_{\mathrm{e}}$ dependence of the photon efficiency is weak, (range $T_{\mathrm{e}}<1.5 \mathrm{eV}$ [42]). Therefore, it can be considered as constant, and the gross erosion is then expressed as:

$\Gamma_{\mathrm{CH}_{4}}=\frac{1}{\Pi_{\text {phot }}} \phi_{\mathrm{A} \rightarrow \mathrm{X}}^{\mathrm{CH}} \propto \frac{1}{f_{\text {quench }}} \phi_{\mathrm{A} \rightarrow \mathrm{X}}^{\mathrm{CH}}$.

The measured gross erosion is presented in Table 1, at the start of the plasma and at the end. The reason for two values is that the gross erosion drops during the plasma exposure due to plasmainduced surface modification (e.g. by film or nano/micro-structure growth), and the resulting change in surface properties. This is further explained in Sec. 4.

Table 1: The exposure conditions of the samples - peak surface temperature $\left(T_{\mathrm{s}, \mathrm{peak}}\right)$, ion energy $\left(E_{\mathrm{ion}}\right)$, ion flux $\left(\Gamma_{\mathrm{i}}\right)$ and the initial and final gross erosion rate $\left(\Gamma_{\mathrm{CH} 4}\right)$ - and indication of the structures which were formed. The structures include MP-i (microparticles with a impurity in the core), columnar structures (C), and microparticles (MP). If the suffix '(l)' is added, only a low surface coverage of these structures is observed. 


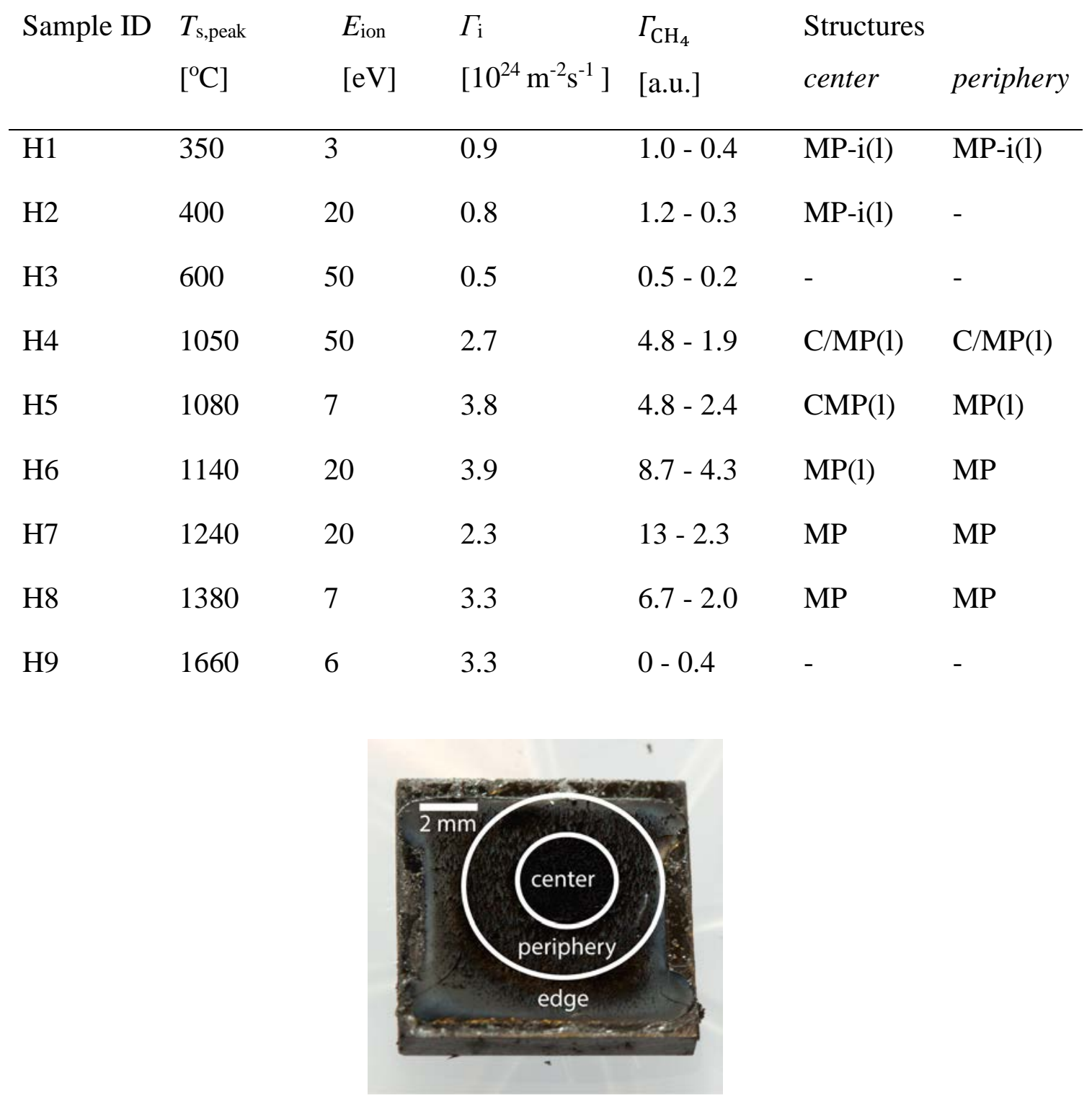

Fig. 2: Example of a sample after plasma exposure showing three distinct regions: center, periphery, and edge.

In Table 1, we show that the magnitude of the gross erosion strongly determines the type of structures that grow. Despite the difference in plasma conditions, the gross erosion is strongly correlated to the peak surface temperature (thus this ordering is used in the table). Samples, which were exposed with a central sample temperature below $600{ }^{\circ} \mathrm{C}$ show only a few MPs (Fig. 3a). At a sample temperature of $\sim 1050-1080^{\circ} \mathrm{C}$ again few MPs (Fig. 3b) are observed and the surrounding surface is additionally covered with columnar structures that consist of CNWs (Fig. 3c in Fig. 3b). At a sample temperature of about $\sim 1140-1380{ }^{\circ} \mathrm{C}$ the center of the samples appears to be 
significantly covered with MPs and agglomerates (Fig. 3d). At sample temperatures above 1600 ${ }^{\circ} \mathrm{C}$, no MPs are observed (Fig. 3e).

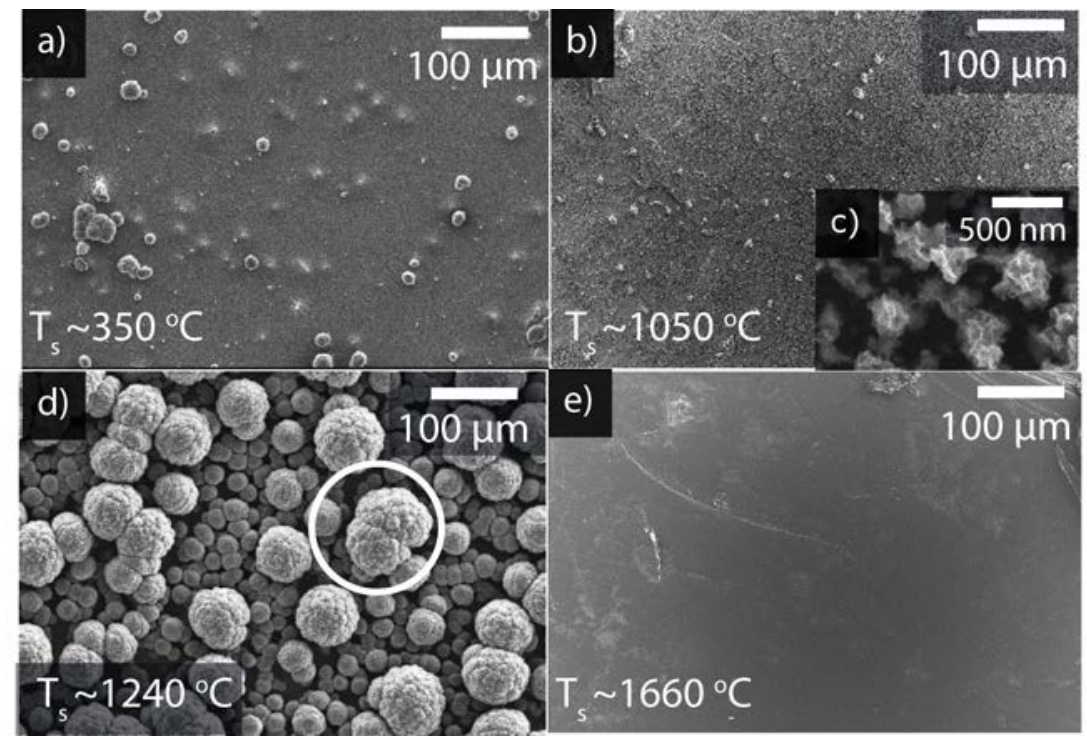

Fig. 3: The SEM images of the types of structures that were grown for different exposure conditions: a) low coverage of microparticles with a impurity in the core (Sample H1), b,c) columnar structures with a low coverage of MPs (Sample H4) d) MPs and agglomeration (circle) of MPs (Sample H7), and e) no structures (Sample H9).

\subsection{Characterization of the microparticles}

The nano/micro-structures were analyzed in more detail in order to explore possible growth mechanisms. Here, we will describe the morphologies in terms of increased surface temperature. In the case of a low surface temperatures $\left(<600{ }^{\circ} \mathrm{C}\right)$, the coverage of MPs is low, i.e., about $\sim 1$ \%. The BSE image of Fig. 4 shows the cross section of one of these MPs that was cut with focused ion beam (FIB) etching. The brighter region at the bottom (indicated by arrows) shows that this MP has a non-carbon impurity particle at the base. The impurity could have several origins, including W/Mo from the plasma source, Mo from the clamping ring surrounding the sample and Si from plasma etching of the windows The exact origin of the impurity is subject of future work. Surrounding the impurity core is a dense carbon region from which columnar structures developed. This particular morphology suggests an impurity seed is required to initiate the formation and the main growth mechanism is by ballistic deposition [47,48], where particles arrive along straightline trajectories. The contribution of positively charged species to the growth can be dominant, 
because the fraction of ionized hydrocarbon species is high (due to the low gross erosion), and the HOPG sample has a negative potential.

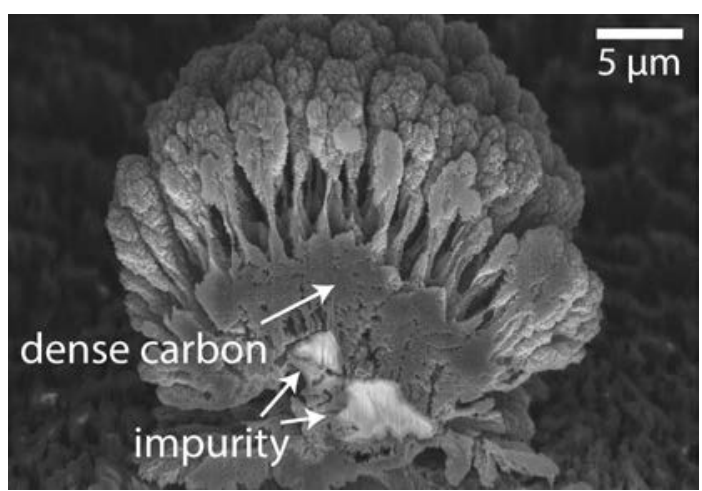

Fig. 4: BSE image of a cross section of a carbon microparticle from temperature range $<600{ }^{\circ} \mathrm{C}$ with a impurity particle at the base.

At a surface temperature of about $1050-1080{ }^{\circ} \mathrm{C}$, the surface coverage with MPs is less than 2 \%. Fig. 5a, shows the cross section of a MP produced in such condition. Inside the particle, a dense off-centric carbon seed is observed from which columnar structures arise in the direction slightly tilted from the normal sample surface. The off-centric seed suggests that the MP has (initially) been grown at the surface. The open region at the left part (white circle) and the spherical shape at the bottom suggest that the particle has been tilted. Surrounding the MP, on the sample surface, columnar structures are observed that have a typical width of few hundred nm and height of $\sim 1 \mu \mathrm{m}$ and appears to consists of CNWs (Fig. 5b,c). The columnar structures indicate that these structures are also grown from the surface. According to our knowledge, CNWs grown from eroded species and reorganization at the surface has not been reported in literature. The growth rate is $40 \mathrm{~nm} / \mathrm{s}$ which is a factor 2 higher than other methods we are aware of [49].

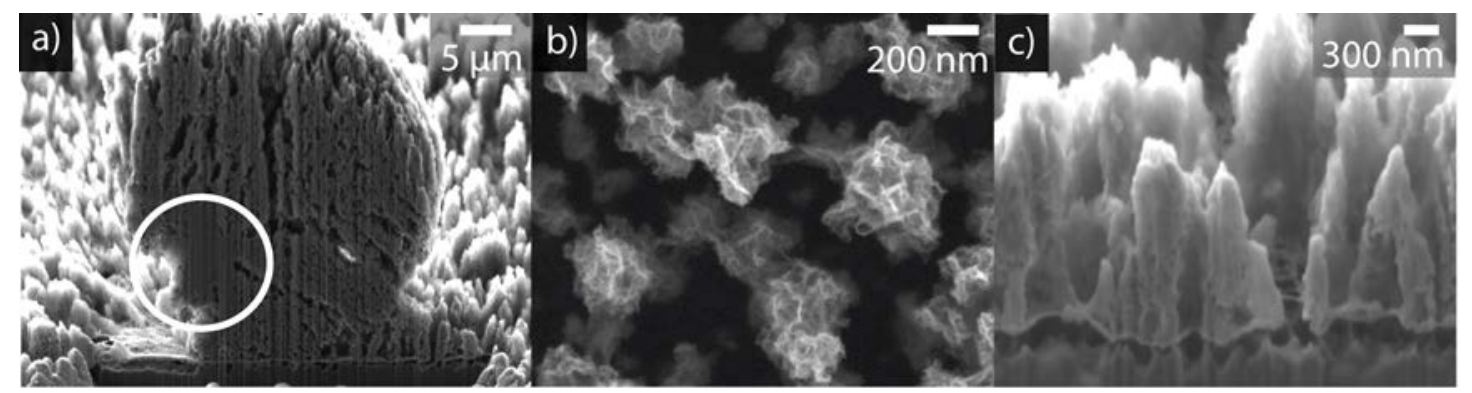


Fig. 5: a) SEM cross-section image of a carbon microparticle from the temperature range 1050$1080{ }^{\circ} \mathrm{C}$ with dense off-center carbon region (marked with circle). b) top-view and c) crosssectional images of columnar structures surrounding the MPs that cover the full surface.

Significant MP growth (24-61\% surface coverage) occurs at a surface temperature of 1140-1380 ${ }^{\circ} \mathrm{C}$. These-MPs can be seen by the naked eye (Fig. 6a) and are clearly distinguished from the substrate (Fig. 6b). The surface comprises wavy carbon nanowalls (Fig. 6c). These particles are similar to those found in a previous work in Pilot PSI, that used fine-grain graphite as sample material [37]. The MPs can be removed either by scratching them off or using a hand air blower. After removal, hills can be observed on the sample surface where MPs were previously located (Fig. 6d). The origin of these hills is discussed in Sec. 4. The sample surface roughness is relatively low compared to the height $(\sim 15 \mu \mathrm{m})$ of the MPs. In the previous work, the samples showed an erosion-dominated zone with spiked structures and a deposition-dominated zone with MPs [37]. These zones are however not observed in the samples that exhibit MPs of this work. This can be related to the smaller samples size compared to previous work, which minimizes the gradient in the ion flux and surface temperature, resulting in more uniform erosion across the sample.

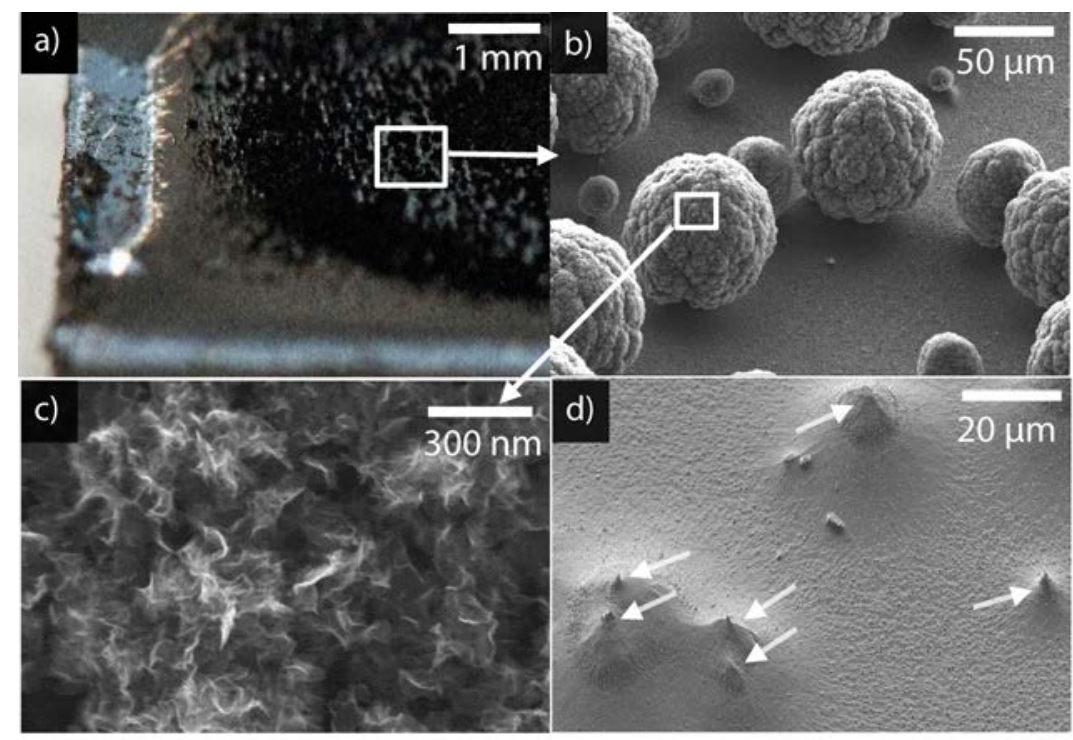

Fig. 6: a) Camera image of a sample after exposure to hydrogen plasma. SEM images of b) MPs c) carbon nanowalls on the surface of a MP d) surface after removal of the MPs (other sample), revealing hills where previous MP were located (indicated by arrows). 
The cross section of one of the particles was obtained by FIB etching and is depicted in Fig. 7. There are three distinct regions: a central core, and two surrounding elongated layers around the central core. The core and layer 1 are delineated by a more porous region of carbon, while layer 1 and layer 2 are delineated by a denser region of carbon. The number of layers correlates to the number of plasma discharges, i.e. the core particle was formed during the first plasma and the two surrounding layers were accreted during two consecutive plasmas exposures. The spherical core $(\sim 9 \mu \mathrm{m})$ indicates a growth in the gas phase while the elongated outer rings are consistent with accretion of hydrocarbon radicals likely by diffusion-limited aggregation [50], i.e. aggregation occurs by diffusion of the (neutral) growth species to the surface. Indeed, due to the higher erosion rate in this temperature regime, the hydrocarbon molecule concentration is higher. This results in a lower ionization degree, so a higher fraction of neutral radicals. Interestingly, the growth rate (estimated by $r_{\text {layer }} / t_{\text {shot }}$ ) in the two outer layers is similar: 0.5 and $0.4 \mu \mathrm{m} / \mathrm{s}$ for layer 1 and layer 2 respectively. The growth rate of the core (formed in the gas phase) may be much larger than 0.6 $\mu \mathrm{m} / \mathrm{s}$ however, depending on when the particle was nucleated. These growth rates are much higher than reported for conventional $\mathrm{RF} \mathrm{Ar} / \mathrm{C}_{2} \mathrm{H}_{2}$ discharges, where the particle growth rate is $<2 \mathrm{~nm} / \mathrm{s}$ [51]. The rate is however, comparable to a-C:H deposition by an expanding cascaded arc plasma $\left(\mathrm{Ar} / \mathrm{CH}_{4}\right)$ under relatively high vessel pressure [52] $\left(10^{3} \mathrm{~Pa}\right.$ compared to $0.2 \mathrm{~Pa}$ in Pilot-PSI [31]).

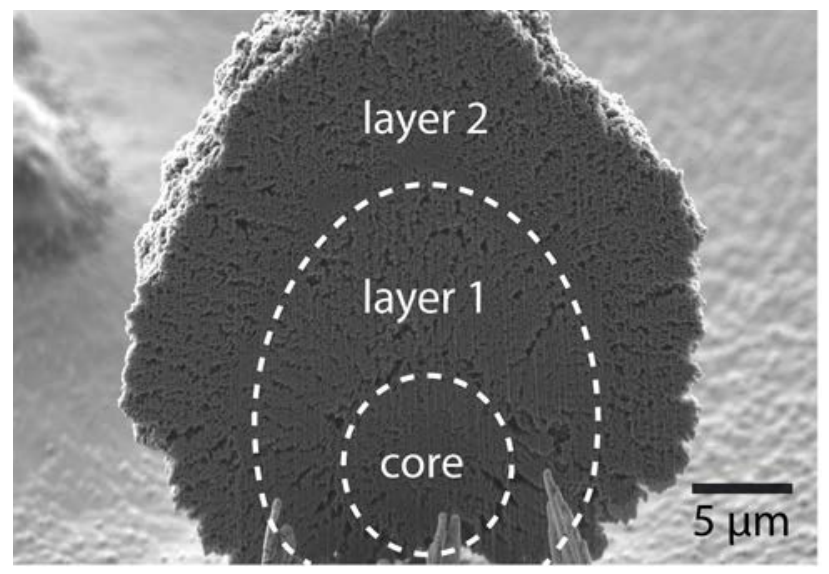

Fig. 7: SEM image of a microparticle cross section (diameter $\sim 30 \mu \mathrm{m}$ ) grown in the sample temperature range, $1140-1380{ }^{\circ} \mathrm{C}$. The two (white) guidelines separate the three different growth regions. The three spikes at the bottom are an artifact due to the FIB milling.

The interior of a MP was analyzed with transmission electron microscopy (TEM). A slice of the middle section of one of them ( $\sim \mu$ m diameter) was prepared by FIB milling, which is depicted 
in Fig. 8a. The slice thickness is about $\sim 1 \mu \mathrm{m}$. Inside, a spherical structure can be observed. It is supported on a pillar 'base', which was attached to the surface (similar base structures are visible in Fig. 6d). Inside this spherical structure a core particle (black dashed circle) can be observed with a diameter of $\sim 1 \mu \mathrm{m}$ (Fig. 8b). Higher resolution shows that the core mainly comprises an agglomeration of onion-shaped carbon nanoparticles (CNPs) with a diameter of $<10 \mathrm{~nm}$ as clearly shown in Fig. 8c). The size and shape of these CNPs are similar as previously found inside the graphitic layers that were scratched off from the surface [37]. This is an important finding, since the spherical geometry of these CNPs and their internal structure is a clear indication of a growth in gas phase [53]. The presence of CNPs is also supported by selected area electron diffraction (see Fig. S2 in the supplementary data). The diffraction rings inside the core are broadened and continuous, consistent with the smaller and round crystalline graphitic particles. In the periphery surrounding the core, graphitic layers are observed (Fig. 8b). A detailed view (Fig. 8d) shows fringe patterns of wavy carbon nanowall structures, consistent with the CNWs found on the surface with SEM (Fig. 6c). The fringes correspond to graphene layers. Their typical number is about 1015; the total thickness is about 4-6 nm and the typical length is several tens of nanometers. The inter-fringe distance is $0.37-0.38 \mathrm{~nm}$, which is slightly higher than the theoretical value of graphene layers in $(\sim 0.34 \mathrm{~nm})$ graphite, indicating structural defects. In both the SEM and TEM images, the presence of pores is clearly visible. The apparent pore size ranges from several to few hundred nanometers. 


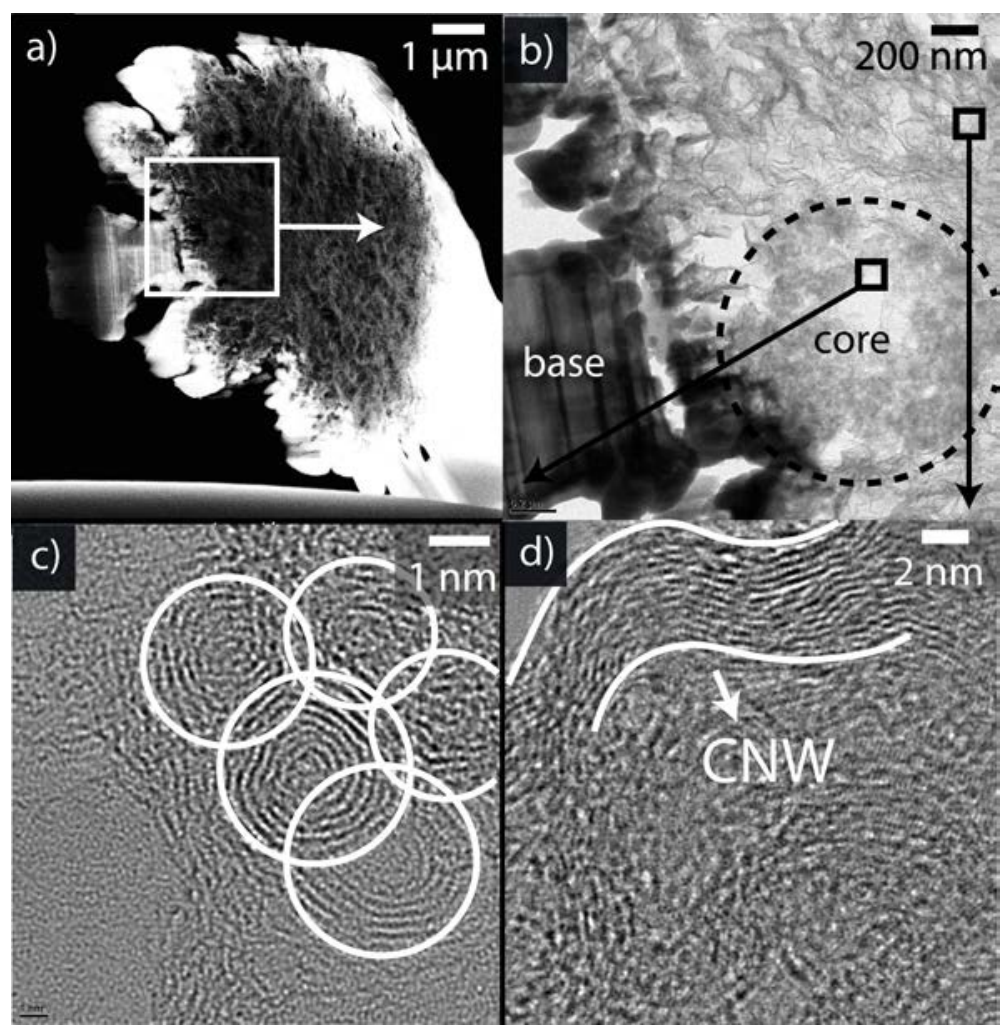

Fig. 8: a) STEM image of a slice of the middle section of a MP. The columnar structure on the left side is where the particle was connected to the substrate. b) TEM images show that the center of the particle consists of relative dense carbon core, while the surrounding comprises of crumpled graphitic layers. c) a zoom-in on the interior of the core, revealing an additional contribution of onion-shaped carbon nanoparticle. d) HRTEM image of graphitic layers in the region outside the core

To gain more insight into the chemical composition and structure of these MPs and their surrounding surface (easily distinguishable as shown in Fig. 6b), additional surface analysis was performed by X-ray photoelectron spectroscopy (XPS). The general XPS spectrum (Fig. 9a) reveals the presence of carbon and oxygen (likely due to oxidation in air), consistent with the EDX measurements (Fig. S3 in the supplementary data). Fig. 9b shows a high-resolution C 1s core level spectrum. The C 1s peak position measured at the MP and its surrounding area, is only minimally shifted $(0.05 \mathrm{eV})$ with respect to the HOPG reference sample, and the shape is very similar. From this we conclude that the $\mathrm{sp}^{3} / \mathrm{sp}^{2}$ fraction of the MPs and its surrounding area is approximately equal to the HOPG reference, which is essentially graphitic, i.e. $100 \% \mathrm{sp}^{2}$ within an error bar for XPS of typically $10 \%$ [54]. With this bound for the $\mathrm{sp}^{3} / \mathrm{sp}^{2}$ fraction, the composition of the MPs 
on the ternary phase diagram is in between pure graphite $\left(0-5 \% \mathrm{sp}^{3} / \mathrm{sp}^{2}\right)$ and sputtered a-C(:H) films $\left(10-40 \% \mathrm{sp}^{3} / \mathrm{sp}^{2}\right)[55,56]$. The reason for the graphitic structures instead of amorphous carbon can be explained by the higher resilience of graphite against hydrogen ion impacts than amorphous carbon [57]; the amorphous phase is sputtered faster by the hydrogen ions. Moreover, at elevated temperatures graphite starts to anneal, resulting in dominance of the $\mathrm{sp}^{2}$ hybridization state (graphite) [58].
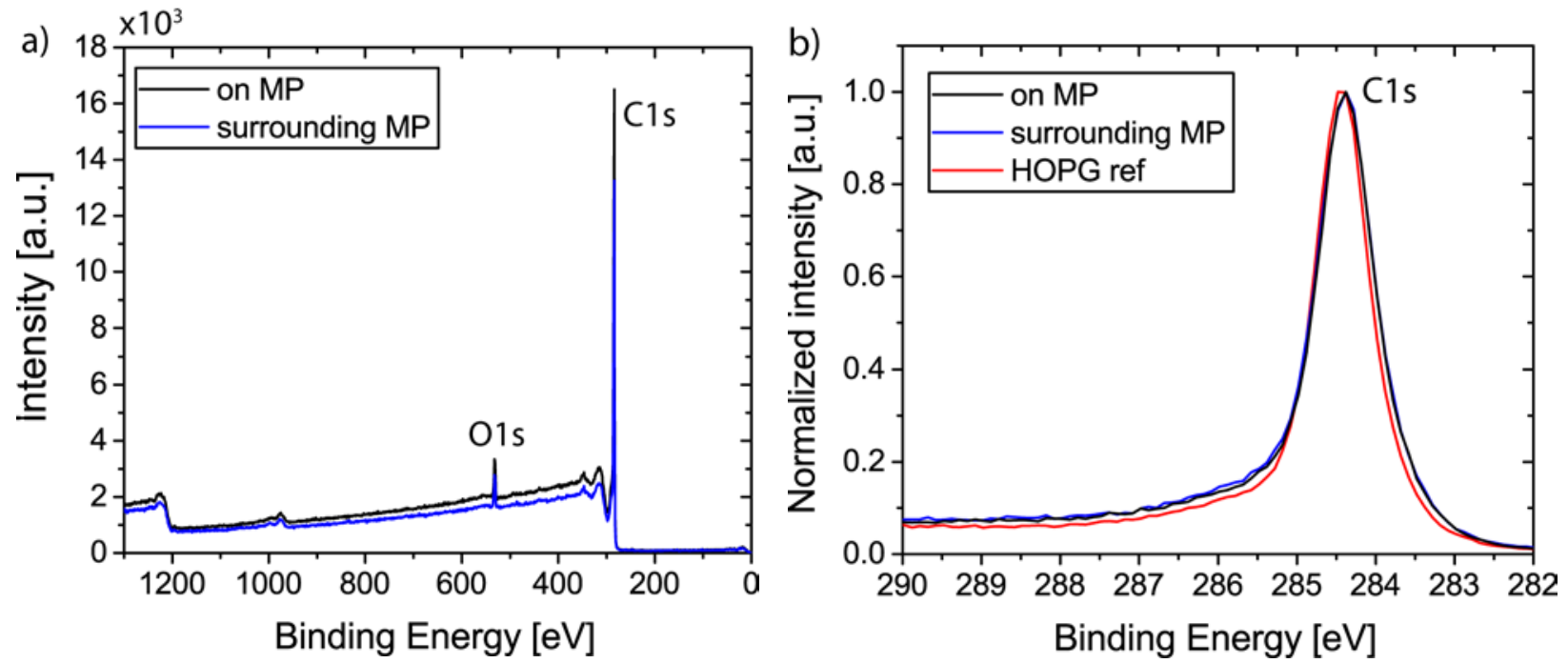

Fig. 9: XPS spectra at different locations on the sample. a) The overview spectrum shows that the surface predominantly consists of carbon. The oxygen peak can be attributed to the post-plasma sample exposure. b) The C1s peak.

Lastly, Raman spectroscopy was performed to obtain more detailed information on the crystal structure of the MPs as well as on the surrounding sample surface. A typical spectrum is depicted in Fig. 10. Two strong peaks at $1327 \mathrm{~cm}^{-1}$ and $1580 \mathrm{~cm}^{-1}$ are observed, and a small shoulder peak at $1620 \mathrm{~cm}^{-1}$, which correspond to the D, G, and D' band respectively. The G-band peak is related to graphite, while the $\mathrm{D}$ and $\mathrm{D}$ ' bands indicate domain edges of graphene layers $[59,60]$. The surface surrounding the MPs shows a spectrum with a relative small D band peak, but unchanged width of the G-band peak compared to the HOPG reference. This indicates that the surface is damaged HOPG caused by the ion irradiation. The microparticle show a spectrum with an intensity ratio between the G- and D-band of $I_{\mathrm{D}} / I_{\mathrm{G}} \sim 2$ and a G-band width of $\sim 50 \mathrm{~cm}^{-1}$. The $I_{\mathrm{D}} / I_{\mathrm{G}}$ ratio is similar to typical (predominately) vertical aligned CNWs grown on metal surfaces, but the G-band width is higher, which may be explained by the larger stress and graphitic disorder in the MPs 
[61]. The spectrum is very similar to a-C:H films deposited by an expanding cascaded arc plasma $\left(\mathrm{Ar} / \mathrm{CH}_{4}\right)$ [62], which comprises similarly shaped fractal CNW structures as observed on the MP surfaces of this study (Fig. 6c). The crystallite size $L_{c}$ in the MPs is estimated by using the $I_{D} / I_{G}$ ratio and empirical formula $L_{\mathrm{c}}[\AA]=44 /\left(I_{\mathrm{D}} / I_{\mathrm{G}}\right)$ [61], and reveals an average value of $22 \AA$.

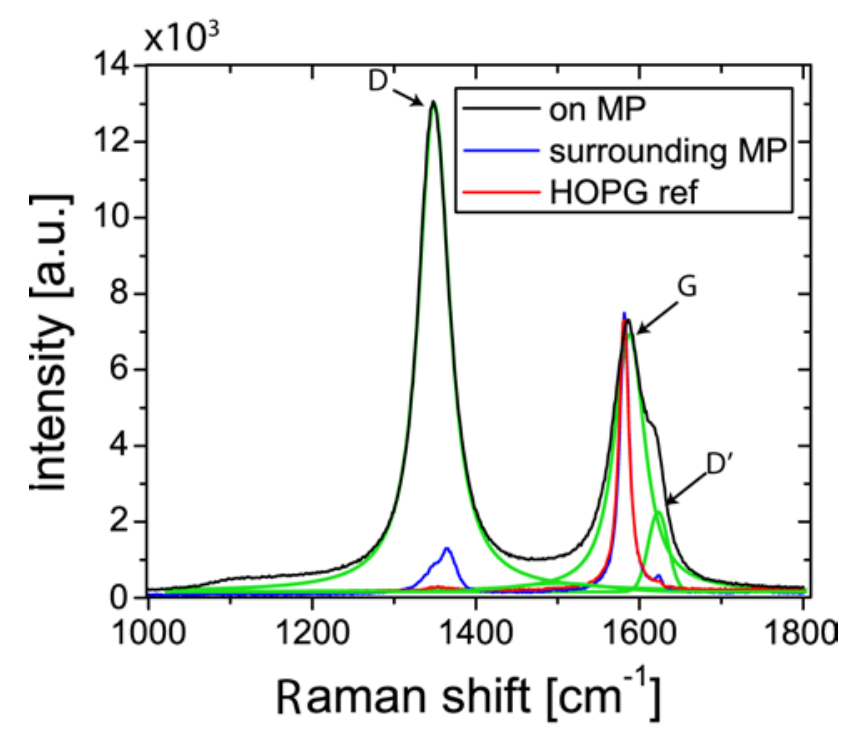

Fig. 10: Raman spectrum of different locations near the center of the sample. The green lines indicate the D, D' and G peaks fitted by a gradient-expansion algorithm for the spectrum 'on top of the microparticle'.

The MP size distribution is an important characteristic for future applications. This distribution can easily be determined by using a SEM overview image of the MPs, Fig. 3d. The obtained result is shown in Fig. 11 and can be described by the two log-normal distribution functions. The first and dominant size distribution has a mean value of $\sim 15 \mu \mathrm{m}$, similarly to previous work [37]. Considering the total discharge duration of $75 \mathrm{~s}$, the mean size can be achieved with an average growth rate of $0.2 \mu \mathrm{m} / \mathrm{s}$. The second size distribution can also be distinguished and has a mean value of $\sim 60 \mu \mathrm{m}$, consistently with Ref. [37]. The latter particles are less spherical and can be the result of agglomeration as depicted in Fig. 3d. 


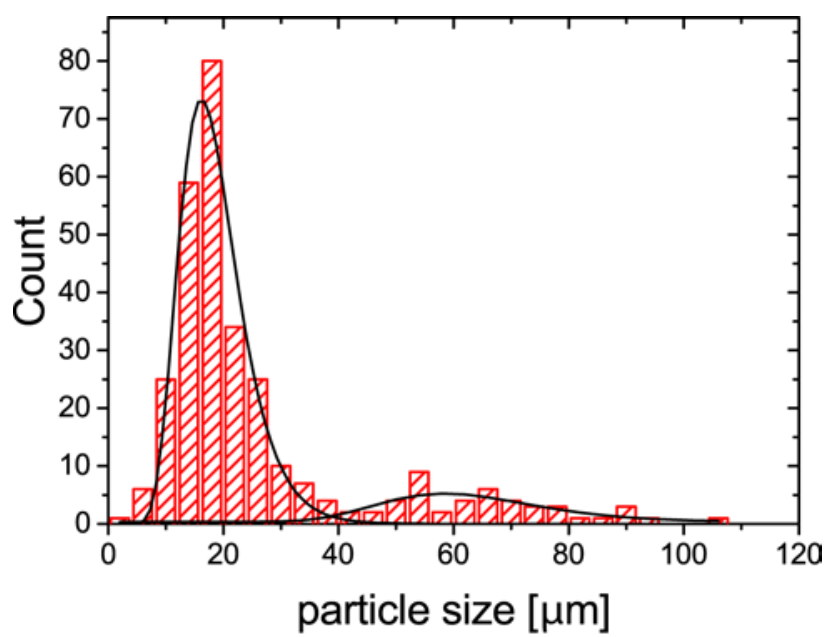

Fig. 11: Typical particle size histogram showing two-size distributions. The black lines are the fits with a log-normal distribution function.

The surface area and pore characteristics of the MPs were obtained by analyzing the $\mathrm{N}_{2}$ sorption isotherms. Since the quantity required for an accurate analysis is significant, we used MP materials from multiple samples of previous work (with graphite as substrate), which had a similar size distribution, internal structure, $\mathrm{sp}^{3} / \mathrm{sp}^{2}$ fraction, and $I_{\mathrm{D}} / I_{\mathrm{G}}$ ratio. Fig. 12a shows sorption isotherms, i.e. the adsorbed quantity $\mathrm{N}_{2}$ gas in the MPs as function of the pressure $\mathrm{p}$ normalized by the saturation pressure $\mathrm{p}_{0}$. The relative rapid uptake of $\mathrm{N}_{2}$ from 0 to $0.01 \mathrm{p} / \mathrm{p}_{0}$ suggests (some) microporosity (pore size $<2 \mathrm{~nm}$ [5]). The continuous increase of adsorption between 0.05 and 0.3 $\mathrm{p} / \mathrm{p}_{0}$ indicates the presence of mesopores. The sharp rise of the adsorbed volume near the saturation pressure suggests the existence of large mesopores and macropores. Lastly, a step-down in the desorption branch is observed near $0.45 \mathrm{p} / \mathrm{p}_{0}$, which can be explained by cavitation-induced evaporation [63]. The shape of this isotherm corresponds to a type IV - typical for mesoporous adsorbents - with H3 hysteresis loop, which can party be explained by incomplete filling of the pores [64]. The co-existence of micro-, meso- and macropores can also be observed in the electron microscopy images depicted in Fig. 7 and Fig. 8b,d. In contrast to active carbon materials with only micropores, the abundant meso-/macropores allow for better mass transport [65]. The specific BET surface area of the MPs obtained in the range 0.07-0.2 p/po is $150 \pm 30 \mathrm{~m}^{2} \mathrm{~g}^{-1}$. This is of similar order of magnitude as the graphene microspheres presented in Ref. [16]. The pore size distribution of the mesopores (assuming cylindrical pores) was obtained by applying the $\mathrm{BJH}$ model on the adsorption branch of the isotherm, and is depicted in Fig. 12b (i.e., the plot shows the incremental adsorbed volume $(d V)$ normalized by the pore size interval $(d w)$ for each pore 
size). It indicated that the pore size is widely distributed within 5-60 $\mathrm{nm}$. The cumulative pore volume in the range $1.7-300 \mathrm{~nm}$ is $1.0 \pm 0.2 \mathrm{~cm}^{3} \mathrm{~g}^{-1}$. Noteworthy, the actual specific surface area and pore volume may be significantly underestimated; since the MP material was obtained by scraping off samples and thus likely contains small pieces of bulk graphite, this could have led to a substantial overestimation of the sample mass over which the adsorbed volume is normalized.
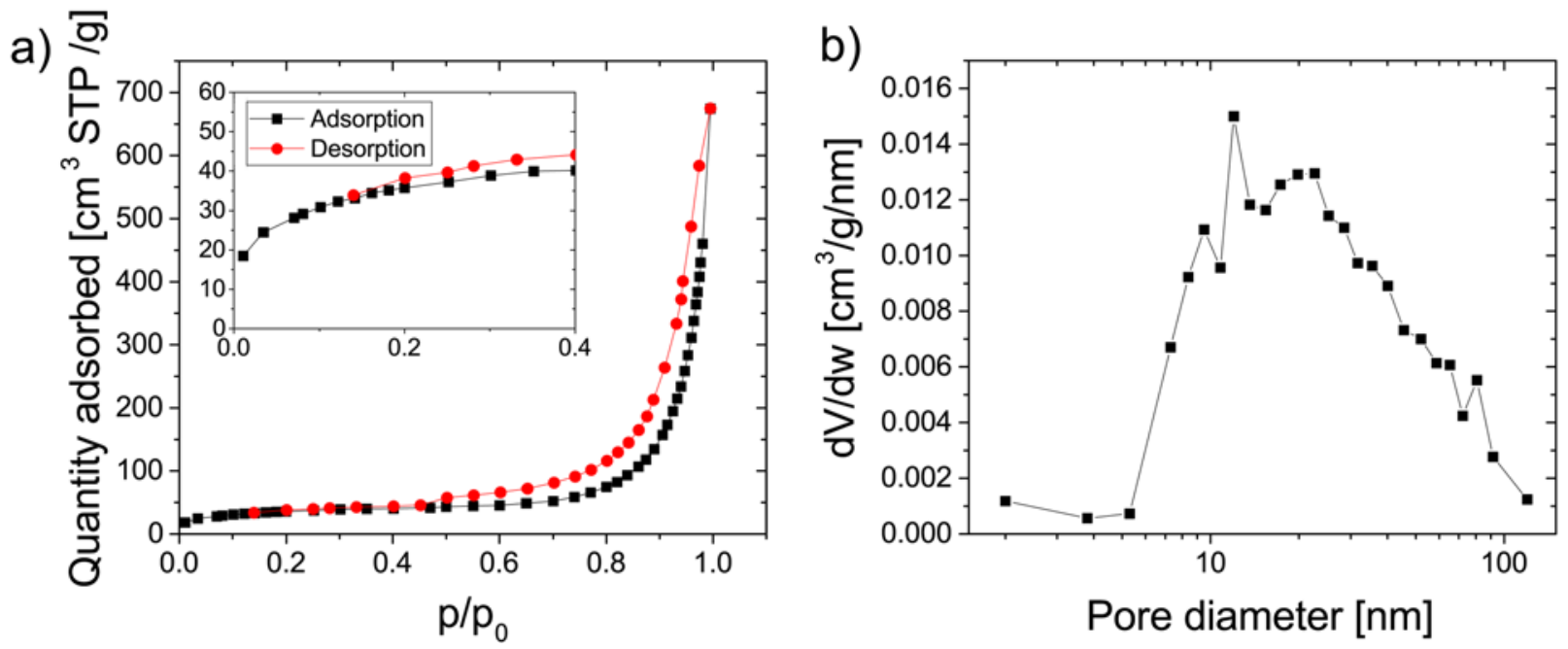

Fig. 12: a) $\mathrm{N}_{2}$ adsorption/desorption isotherms and b) $\mathrm{BJH}$ pore size distribution of the microparticles.

\subsection{In-situ observation of MP growth}

Having described the morphological features of MPs above, we now elaborate on their formation mechanism. In the previous work, it was not justified whether the MP deposition on the sample surface takes place during the plasma discharge or after the end of the plasma [37]. This is difficult to diagnose, since the particles are small $(<15 \mu \mathrm{m})$ and grow very close to the sample $(1-2 \mathrm{~mm})$ where there is a lot of light emission. In this work, we indirectly show when the particles are deposited, by taking advantage of the difference in emissivity of the as-received HOPG surface ( $\left.\varepsilon_{\mathrm{HOPG}} \sim 0.2\right)$ and particles $\left(\varepsilon_{\mathrm{MP}} \sim 0.9\right.$ [66]). The sample surface temperature is measured by the infrared camera ( $T_{I R}$, emissivity dependent) and multi-wavelength pyrometer ( $T_{\text {pyro }}$, emissivity independent). The measured digital level $(D L)$ of the infrared camera in the temperature range $>1000{ }^{\circ} \mathrm{C}$ scales linearly with the surface temperature $\left(T_{\mathrm{IR}}\right)$ and the selected emissivity $(\varepsilon): D L \propto$ $\varepsilon S\left(T_{\mathrm{IR}}(\varepsilon)\right) \propto \varepsilon T_{\mathrm{IR}}(\varepsilon)$, where $S$ is the camera's transfer function from photons to digital level for a black-body surface. By choosing $\varepsilon=\varepsilon_{\mathrm{HOPG}}$ and considering the equality $\varepsilon_{\mathrm{HOPG}} T_{\mathrm{IR}}\left(\varepsilon_{\mathrm{HOPG}}\right)=$ 
$\varepsilon_{\text {surf }} T_{\mathrm{IR}}\left(\varepsilon_{\text {surf }}\right)=\varepsilon_{\text {surf }} T_{\text {pyro }}$, the emissivity of the surface $\left(\varepsilon_{\text {surf }}\right)$ can be calculated from $T_{\text {IR }}$ and $T_{\text {pyro }}$. The obtained emissivity $\varepsilon_{\text {surf }}$ can be used to diagnose the surface texture during the interaction with the plasma. Fig. 13a,b shows the apparent surface temperature from both diagnostics as well as the determined emissivity during the four plasma exposures sample $\mathrm{H} 7$ is subjected to, having respective durations 5, 5, 30 and $35 \mathrm{~s}$. The pyrometer started recording few seconds after plasma initiation due to an instrumental delay. After a total exposure duration of 10 $\mathrm{s}$ the sample emissivity/signal strength starts to change and it saturates within $35 \mathrm{~s}$ to a value equal to those of the particles. The same applies for the signal strength which is proportional to the emissivity [67]. This result can be interpreted by a 2-population (particle and surrounding) model which takes both contributions to the light emission into account (from which the temperature is measured). The proportion of MP light contribution is:

$\frac{I_{\mathrm{MP}}}{I_{\text {surf }}}=\frac{A_{\mathrm{MP}} \varepsilon_{\mathrm{MP}} \sigma T_{\mathrm{MP}}{ }^{4}}{A_{\text {surf }} \varepsilon_{\text {surf }} \sigma T_{\text {surf }}{ }^{4}} \approx 4.5 \frac{A_{\mathrm{MP}}}{A_{\text {surf }}}\left(\frac{T_{\mathrm{MP}}}{T_{\text {surf }}}\right)^{4}$,

in which $\sigma$ is the Stefan-Boltzmann constant, $A_{\mathrm{MP}}$ and $A_{\text {surf }}$ are the surface areas, and $T_{\mathrm{MP}}$ and $T_{\text {surf }}$ are the surface temperatures. Due to the low heat conductivity of the MPs, $T_{\mathrm{MP}}$ is higher than $T_{\text {surf. }}$. This means that while the surface coverage $\left(A_{\mathrm{MP}} / A_{\text {surf }}<50 \%\right)$ is still low $\left(T_{\text {surf }} \sim 1210{ }^{\circ} \mathrm{C}\right)$, the signal may already be dominated by the MPs. The gradual increase of the emissivity indicates that the MPs are continuously deposited, rather than being deposited at the end of a discharge. The deposition starts in less than $35 \mathrm{~s}$ of plasma exposure.

The gross erosion during the plasma exposure is diagnosed by measuring the $\mathrm{CH} \mathrm{A}-\mathrm{X}$ emission intensity, which is depicted in Fig. 13c. The data shows that while the MP are being deposited on the surface, the $\mathrm{CH}$ A-X emission intensity drops and so does the gross erosion by a factor of up to 6 (Table 1). The drop can be explained by the higher surface temperature of the MPs compared to the surrounding surface. For surface temperatures exceeding $1000 \mathrm{~K}$ the gross erosion decreases monotonically with increasing surface temperature [68], because desorption of hydrogen starts to dominate over the release of hydrocarbons from the surface [69]. Thus, surface erosion is essentially a self-limiting process because the deposited particles reduce the erosion locally and in fact act as net-sinks for the recycled species. 


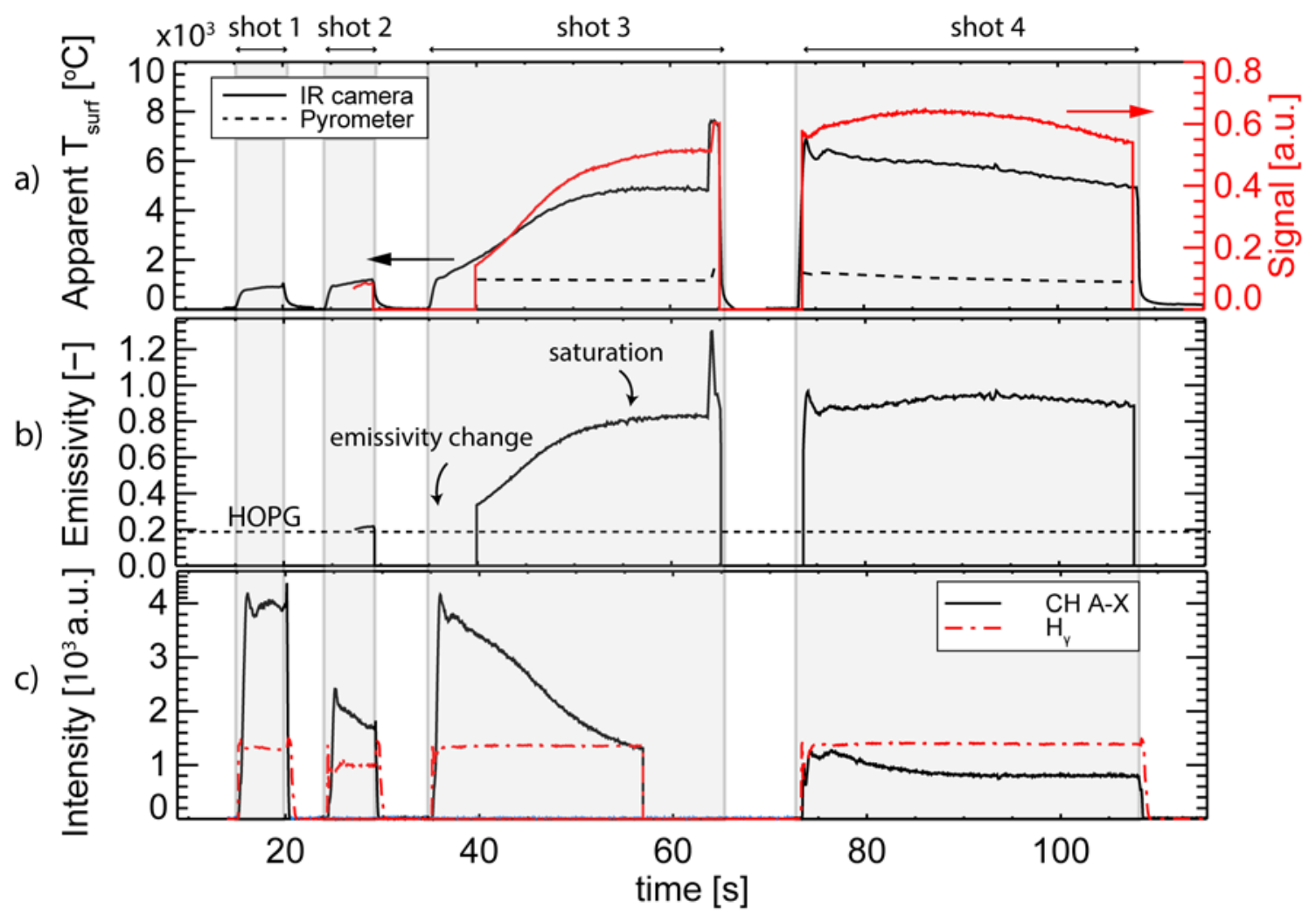

Fig. 13: a) Apparent sample temperature measured by the pyrometer and IR camera during the plasma shots of sample $\mathrm{H} 7$ (assuming a fixed emissivity of 0.2 ). The signal strength of the pyrometer is depicted on the right axis, b) The determined emissivity. c) Emission intensity of $\mathrm{CH}$ A-X Gerö band (black) and Balmer $\mathrm{H}_{\gamma}$ line (red). Two test shots were used to fine-tune the conditions. The sharp drop in the second shot can be attributed to lower plasma conditions $\left(\mathrm{n}_{\mathrm{e}} / \mathrm{T}_{\mathrm{e}}\right)$ and thus lower ion flux and energy.

\section{DISCUSSION}

This section discusses the nucleation mechanisms and growth conditions in more detail. Particle growth by hydrocarbon molecules in plasma is commonly understood to consist of four phases [70]: (1) formation of large ion or neutral precursors (2) nucleation into protoparticles ( 1 nm), (3) agglomeration of protoparticles into larger particles, (4) further growth by surface accretion of radicals and ions. In our case, a similar four-step growth could be identified:

Step 1: 'formation of large hydrocarbon molecules' The hydrogen ion impact leads to chemical erosion resulting in the release of methane and a fraction of larger hydrocarbon molecules in the plasma [54,55], which concentration can be determined by CH A-X emission measurements (Sec. 
3.1). The results show that a minimum concentration, is required for MP growth and this implies that hydrocarbon molecule reactions in the plasma are the driving force for nucleation. Several routes to the formation of large hydrocarbon molecules in methane and acetylene plasmas have been proposed in the literature. In the dusty plasma experiments using $\mathrm{Ar} / \mathrm{C}_{2} \mathrm{H}_{2}$ and $\mathrm{Ar} / \mathrm{CH}_{4}$ discharges [24,30,71] the formation of large ions is understood to occur by negative-neutral reactions with precursor molecule $\mathrm{C}_{2} \mathrm{H}_{\mathrm{x}}{ }^{-}$, which can be formed by dissociative electron attachment of $\mathrm{C}_{2} \mathrm{H}_{\mathrm{x}}$ molecules. Let us note that the gas temperature in these experiments was $T_{\mathrm{g}} \sim 300 \mathrm{~K}$, which is much lower than in Pilot-PSI.

In $\mathrm{Ar} / \mathrm{H}_{2} / \mathrm{CH}_{4}$ discharges used for diamond growth the gas temperature is typically much higher: 1200-4000 K [72]. It was shown that in these conditions large molecules and ions can be formed according to complex successive reactions: hydrogen abstraction, linearization (acetylene formation) and cyclization (formation of polycyclic aromatic hydrocarbons -PAHs- molecules). The same model was also extended to the possibility of positively charged PAHs [72]. The PAHs could subsequently nucleate into particles, which is discussed below. It was also found that the optimal temperature for nucleation in such conditions was 1000-1500 K. This modeling could be a track for our case, since the gas temperature in the vicinity of the sample is $1400-1500 \mathrm{~K}$, assuming $\mathrm{T}_{\text {gas }}=\mathrm{T}_{\text {surf, }}$ and hence overlaps this range.

Step 2: 'nucleation into protoparticles' The TEM images reveal onion-shaped carbon nanoparticles of size $<10 \mathrm{~nm}$ in the core of the MPs. The presence of such CNPs ensures that nucleation in Pilot PSI conditions occurs in the gas phase. Moreover, we assume that the CNP growth could occur by the addition and condensation of PAH molecules [53].

Step 3: 'agglomeration of protoparticles into larger particles' An agglomeration of CNPs was observed in the MP core. The process leading to agglomeration can be understood as follows [24]. In plasmas, nano-microparticles acquire a negative charge because of the higher electron mobility with respect to that of ions. CNPs of few nm have a charge close to unity. This enables stochastic charge fluctuations to briefly produce neutral or even positively charged CNPs [73], leading to higher collision rates. When the CNP density reaches a critical value [24], a rapid agglomeration phase is therefore initiated enhanced by long-range Coulomb interactions which leads to relative big particles and a decrease of their density. While the particles grow, they accumulate a high net negative charge proportionally to their size, which stops coulomb attraction and the growth proceeds by surface accretion. 
Step 4:'further growth by surface accretion' The CNW structures surrounding the MPs core indicate that after nucleation, growth proceeds by the formation of CNWs at the core surface. This step, can lead to a core particle diameter of 2-9 $\mu \mathrm{m}$ as shown on Fig. 7 and Fig. 8a. CNWs are also grown in PECVD processing plasmas with similar gas mixtures (CH4/H2) as in our case [59]. The elongated growth rings around the spherical core of the particle indicates that surface accretion continues after deposition on the substrate, which can lead to the mean particle diameter of $15 \mu \mathrm{m}$ observed in Fig. 11.

Ultimately, the formation of the MPs depends on the limitation of each growth step. First of all, the plasma conditions (e.g. gas temperature) should be such that plasma chemistry reactions lead to the formation of large molecules. A sufficient hydrocarbon molecule density should be present, and thus the gross erosion of the HOPG substrate should be significant. It was shown that graphite erosion strongly depends on the ion flux and surface temperature, consistent with Ref. [43]. At low surface temperatures there is no significant erosion, hence nucleation cannot occur in the plasma. At surface temperature of $\sim 1050{ }^{\circ} \mathrm{C}$, erosion is more significant but it does not lead to nucleation. Instead, CNW structures grow at the surface, which arise due to a complex interplay between erosion and redeposition. At a surface temperature of $1140-1380{ }^{\circ} \mathrm{C}$, the erosion is maximum and the conditions are adequate for nucleation and MPs growth. Most of the eroded carbon material is consumed for MP growth. Let us again notice that, in contrast to the previous work in Pilot PSI [37], no separate erosion-dominated region is observed on the sample surface. In fact, the hill on which the MPs are located (Fig. 6d) indicate that erosion occurs surrounding the MPs, while the MPs are effectively sites of net-deposition. Lastly, if the surface temperatures exceeds $1600{ }^{\circ} \mathrm{C}$, the erosion drops significantly because hydrogen desorption is preferred over hydrocarbon release, thus no material is available to form structures.

A complete process of the particle growth can be summarized in Fig. 14. Hydrogen exposure on HOPG leads to erosion of the carbon sample, and to the release of hydrocarbon species into the plasma. The concentration of hydrocarbons will be significant if a) the gross erosion is high, i.e. the surface temperature is close to the maximum erosion temperature and the ion flux is substantial, and b) the plasma density is sufficient to confine the released hydrocarbons. Depending on among others the gas temperature, the eroded hydrocarbon molecules undergo several plasma chemistry reactions that lead to the formation of larger molecules and ions. These species nucleate into protoparticles and at a sufficiently high density, the protoparticles will agglomerate into relatively 
large particles. Once these larger particles are formed, they will volumetrically grow further by surface accretion of radicals and/or ions, leading to the stacked layers of crumpled carbon nanowalls as observed in Fig. 6c. The emissivity evolution in Fig. 13 shows that at $35 \mathrm{~s}$ these particles could start to continuously fall down to the sample surface. After deposition, the particles continue to grow by surface accretion. Because the surface temperature of the MPs is higher than the surrounding surface, the gross erosion is lower, and hence the particles are effectively a site of net-deposition (see Sec. 3.3). In fact, the microparticles shield the underlying surface from erosion and while they grow, the shadowed area of the underlying surface expands, leading to the hill structures observed in Fig. 6d.

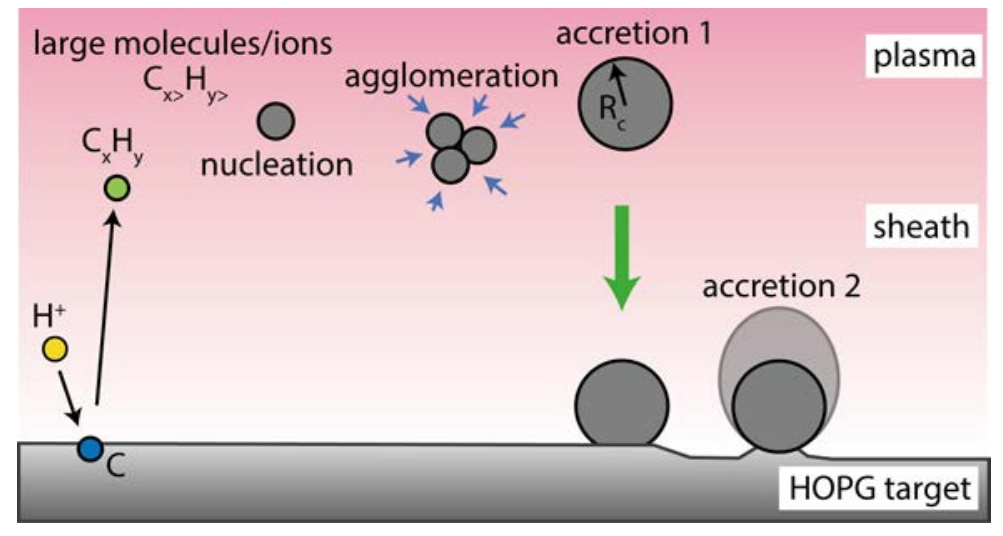

Fig. 14: Model of microparticle growth. Sputtered hydrocarbon molecules migrate into the plasma and through complex chemical reactions form large molecules and/or ions. These nucleate into protoparticles which agglomerate into larger particles. Growth proceeds with surface accretion. After deposition on the sample surface, further growth occurs by a second phase of surface accretion.

Let us notice, that as we have seen in the case of low-temperature samples (see Fig. 5), the seed for growth can also be a impurity particle playing the role of catalyst as usual for the growth of various carbon structure [74].

\section{CONCLUSIONS AND OUTLOOK}

This study evidences the formation of nanostructured carbon-microparticles from the chemical erosion of highly oriented pyrolytic graphite by high-flux hydrogen plasma exposure. The growth conditions were shown to mainly depend on the erosion rate of the surface and the confinement of 
the etched hydrocarbons, and indirectly on the ion flux and plasma density and surface temperature. A minimum concentration was necessary to initiate particle formation. The optimal growth for our setup is achieved at an ion flux of $\sim 2 \cdot 10^{24} \mathrm{~m}^{-2} \mathrm{~s}^{-1}$, a plasma density of $\sim 4 \cdot 10^{20} \mathrm{~m}^{-3}$ and surface temperature of $\sim 1200{ }^{\circ} \mathrm{C}$. The results show that the surface can be covered with particles with an average growth rate of about $0.2 \mu \mathrm{m} / \mathrm{s}$ and that the particle size is log-normal distributed with a mean diameter of $\sim 15 \mu \mathrm{m}$. Transmission electron microscopy, Raman spectroscopy, X-ray photoelectron spectroscopy reveal that the growth occurred by a multi-phase process consisting of gas phase nucleation of hydrocarbon molecules into onion-shaped nanoparticles, subsequent agglomeration into core particles and further growth by accretion of graphitic layers. Comparison of infrared tomography and pyrometry measurements show that particle deposition occurs continuously during the discharge after a minimum exposure duration. The use of highly oriented pyrolytic graphite instead of polycrystalline graphite samples enabled us to identify that after deposition, growth proceeds by further accretion, i.e. the particles are effectively a site of net-deposition of nearby etched hydrocarbons. High resolution transmission electron microscopy shows that the graphitic structures inside the particles are crumpled carbon nanowalls. Analysis of $\mathrm{N}_{2}$ gas sorption isotherms shows sufficient meso- and macropores for fast mass transport. In conclusions, this one-step fast processing technique could open a novel synthesis route for microparticle-substrate systems that can simultaneously function as charge storing material and current collector for electrochemical applications.

\section{ACKNOWLEDGEMENTS}

This work is part of the research program of the Foundation for Fundamental Research on Matter (FOM), which is part of the Netherlands Organization for Scientific Research (NWO). The authors thank DIFFER technical staff for their professional skill and dedicated support, Laurent Marot and Daniel Mathys for performing SEM analysis, and Peter Lodewyckx for providing support on the interpretation of the sorption isotherm data.

\section{APPENDIX A: SUPPLEMENTARY DATA}

Supplementary data related to this article can be found at https://dx.doi.org/<>

\section{REFERENCES}

[1] P. Poizot, S. Laruelle, S. Grugeon, L. Dupont, J. Tarascon, Nano-sized transition-metal 
oxides as negative-electrode materials for lithium-ion batteries, Nature 407 (2000) 496499. doi:10.1038/35035045.

[2] A.S. Arico, P. Bruce, B. Scrosati, J.-M. Tarascon, W. van Schalkwijk, Nanostructured materials for advanced energy conversion and storage devices, Nat Mater 4 (2005) 366377. doi:10.1038/nmat1368.

[3] A. Manthiram, A. Vadivel Murugan, A. Sarkar, T. Muraliganth, Nanostructured electrode materials for electrochemical energy storage and conversion, Energy Environ. Sci. 1 (2008) 621-638. doi:10.1039/b811802g.

[4] E. Frackowiak, F. Béguin, Carbon materials for the electrochemical storage of energy in capacitors, Carbon N. Y. 39 (2001) 937-950. doi:10.1016/S0008-6223(00)00183-4.

[5] J. Rouquerol, D. Avnir, C.W. Fairbridge, D.H. Everett, J.M. Haynes, N. Pernicone, et al., Recommendations for the characterization of porous solids (Technical Report), Pure Appl. Chem. 66 (1994) 1739-1758. doi:10.1351/pac199466081739.

[6] J. Balach, M.M. Bruno, N.G. Cotella, D.F. Acevedo, C.A. Barbero, Electrostatic selfassembly of hierarchical porous carbon microparticles, J. Power Sources 199 (2012) 386394. doi:10.1016/j.jpowsour.2011.10.029.

[7] S.L. Candelaria, Y. Shao, W. Zhou, X. Li, J. Xiao, J.G. Zhang, et al., Nanostructured carbon for energy storage and conversion, Nano Energy 1 (2012) 195-220. doi:10.1016/j.nanoen.2011.11.006.

[8] H. Marsh, F. Rodríguez-Reinoso, Activated Carbon, Elsevier, Amsterdam, 2006. doi:10.1016/B978-008044463-5/50015-7.

[9] G. Cao, Nanostructures and Nanomaterials - Synthesis, Properties and Applications, Imperial College Press, London, 2004. doi:10.1142/9781860945960.

[10] K.P. Gierszal, T.W. Kim, R. Ryoo, M. Jaroniec, Adsorption and structural properties of ordered mesoporous carbons synthesized by using various carbon precursors and ordered siliceous P6mm and Ia(3)over-bard mesostructures as templates, J. Phys. Chem. B 109 (2005) 23263-23268. doi:10.1021/jp054562m.

[11] L. Wang, C. Yang, S. Dou, S. Wang, J. Zhang, X. Gao, et al., Nitrogen-doped hierarchically porous carbon networks: synthesis and applications in lithium-ion battery, sodium-ion battery and zinc-air battery, Electrochim. Acta 219 (2016) 592-603.

[12] E. Ramasamy, J. Chun, J. Lee, Soft-template synthesized ordered mesoporous carbon 
counter electrodes for dye-sensitized solar cells, Carbon N. Y. 48 (2010) 4563-4565. doi:10.1016/j.carbon.2010.07.030.

[13] K.S. Novoselov, A.K. Geim, S. V Morozov, D. Jiang, Y. Zhang, S. V Dubonos, et al., Electric field effect in atomically thin carbon films., Science 306 (2004) 666-9. doi:10.1126/science.1102896.

[14] K.S. Novoselov, A.K. Geim, S. V Morozov, D. Jiang, M.I. Katsnelson, I. V Grigorieva, et al., Two-dimensional gas of massless Dirac fermions in graphene, Nature 438 (2005) 197200. doi:10.1038/nature04233.

[15] A.K. Geim, K.S. Novoselov, The rise of graphene, Nat. Mater. 6 (2007) 183-91. doi:10.1038/nmat1849.

[16] S.H. Park, H.K. Kim, S.B. Yoon, C.W. Lee, D. Ahn, S.I. Lee, et al., Spray-assisted deepfrying process for the in situ spherical assembly of graphene for energy-storage devices, Chem. Mater. 27 (2015) 457-465. doi:10.1021/cm5034244.

[17] G.S. Selwyn, J. Singh, R.S. Bennett, In situ laser diagnostic studies of plasma-generated particulate contamination, J. Vac. Sci. Technol. A Vacuum, Surfaces, Film. 7 (1989) 2758. doi:10.1116/1.576175.

[18] K.G. Spears, T.J. Robinson, R.M. Roth, Particle distributions and laser-particle interactions in an RF discharge of silane, IEEE Trans. Plasma Sci. 14 (1986) 179-187. doi:10.1109/TPS.1986.4316521.

[19] N. Aggadi, C. Arnas, F. Bénédic, C. Dominique, X. Duten, F. Silva, et al., Structural and chemical characterisation of soot particles formed in $\mathrm{Ar} / \mathrm{H} 2 / \mathrm{CH} 4$ microwave discharges during nanocrystalline diamond film synthesis, Diam. Relat. Mater. 15 (2006) 908-912. doi:10.1016/j.diamond.2005.11.044.

[20] Z. Bo, Y. Yang, J. Chen, K. Yu, J. Yan, K. Cen, Plasma-enhanced chemical vapor deposition synthesis of vertically oriented graphene nanosheets, Nanoscale 5 (2013) 51805204. doi:10.1039/c3nr33449j.

[21] L. Boufendi, A. Plain, J.P. Blondeau, A. Bouchoule, C. Laure, M. Toogood, Measurements of particle size kinetics from nanometer to micrometer scale in a low-pressure argon-silane radio-frequency discharge, Appl. Phys. Lett. 60 (1992) 169-171. doi:10.1063/1.106981.

[22] C. Deschenaux, A. Affolter, D. Magni, C. Hollenstein, P. Fayet, Investigations of CH4, C2H2 and C2H4 dusty RF plasmas by means of FTIR absorption spectroscopy and mass 
spectrometry, J. Phys. D. Appl. Phys. 32 (1999) 1876-1886. doi:10.1088/00223727/32/15/316.

[23] J. Berndt, S. Hong, E. Kovačević, I. Stefanović, J. Winter, Dust particle formation in low pressure $\mathrm{Ar} / \mathrm{CH} 4$ and $\mathrm{Ar} / \mathrm{C} 2 \mathrm{H} 2$ discharges used for thin film deposition, User Model. UserAdapt. Interact. 71 (2003) 377-390. doi:10.1016/S0042-207X(02)00767-4.

[24] S. Hong, J. Berndt, J. Winter, Growth precursors and dynamics of dust particle formation in the Ar / CH 4 and Ar / C 2 H 2 plasmas, Plasma Sources Sci. Technol. 12 (2003) 46-52. doi:10.1088/0963-0252/12/1/306.

[25] J.-C. Schauer, S. Hong, J. Winter, Electrical measurements in dusty plasmas as a detection method for the early phase of particle formation, Plasma Sources Sci. Technol. 13 (2004) 636-645. doi:10.1088/0963-0252/13/4/012.

[26] C. Arnas, A.A. Mouberi, Thermal balance of carbon nanoparticles in sputtering discharges, J. Appl. Phys. 105 (2009) 63301. doi:10.1063/1.3081640.

[27] C. Arnas, A. Michau, G. Lombardi, L. Couëdel, K. Kumar K, Effects of the growth and the charge of carbon nanoparticles on direct current discharges, Phys. Plasmas 20 (2013) 13705. doi:10.1063/1.4776681.

[28] A. Michau, C. Arnas, G. Lombardi, X. Bonnin, K. Hassouni, Nanoparticle formation and dusty plasma effects in DC sputtering discharge with graphite cathode, Plasma Sources Sci. Technol. 25 (2016) 15019. doi:10.1088/0963-0252/25/1/015019.

[29] J. Winter, Dust in fusion devices - experimental evidence, possible sources and consequences, Plasma Phys. Control. Fusion 40 (1998) 1201-1210. doi:10.1088/0741$3335 / 40 / 6 / 022$.

[30] J. Winter, Dust in fusion devices-a multi-faceted problem connecting high- and lowtemperature plasma physics, Plasma Phys. Control. Fusion 46 (2004) B583-B592. doi:10.1088/0741-3335/46/12B/047.

[31] K. Bystrov, M.C.M. Van De Sanden, C. Arnas, L. Marot, D. Mathys, F. Liu, et al., Spontaneous synthesis of carbon nanowalls, nanotubes and nanotips using high flux density plasmas, Carbon N. Y. 68 (2014) 695-707. doi:10.1016/j.carbon.2013.11.051.

[32] N. Ohno, M. Yoshimi, M. Tokitani, S. Takamura, K. Tokunaga, N. Yoshida, Spherical cauliflower-like carbon dust formed by interaction between deuterium plasma and graphite target and its internal structure, J. Nucl. Mater. 390-391 (2009) 61-64. 
doi:10.1016/j.jnucmat.2009.01.051.

[33] V. Ruiz, C. Blanco, M. Granda, R. Menéndez, R. Santamaría, Influence of electrode preparation on the electrochemical behaviour of carbon-based supercapacitors, J. Appl. Electrochem. 37 (2007) 717-721. doi:10.1007/s10800-007-9305-5.

[34] S. Yoon, J. Lee, T. Hyeon, S.M. Oh, Electric Double-Layer Capacitor Performance of a New Mesoporous Carbon, J. Electrochem. Soc. 147 (2000) 2507-2512. doi:10.1149/1.1393561.

[35] T.-C. Weng, H. Teng, Characterization of High Porosity Carbon Electrodes Derived from Mesophase Pitch for Electric Double-Layer Capacitors, J. Electrochem. Soc. 148 (2001) A368-A373. doi:10.1149/1.1357171.

[36] J. Gamby, P.L. Taberna, P. Simon, J.F. Fauvarque, M. Chesneau, Studies and characterisations of various activated carbons used for carbon/carbon supercapacitors, J. Power Sources 101 (2001) 109-116. doi:10.1016/S0378-7753(01)00707-8.

[37] K. Bystrov, L. van der Vegt, G. De Temmerman, C. Arnas, L. Marot, Reorganization of graphite surfaces into carbon micro- and nanoparticles under high flux hydrogen plasma bombardment, J. Vac. Sci. Technol. A Vacuum, Surfaces, Film. 31 (2013) 11303. doi:10.1116/1.4769733.

[38] G.J. Van Rooij, V.P. Veremiyenko, W.J. Goedheer, B. De Groot, A.W. Kleyn, P.H.M. Smeets, et al., Extreme hydrogen plasma densities achieved in a linear plasma generator, Appl. Phys. Lett. 90 (2007) 11-13. doi:10.1063/1.2716208.

[39] G. De Temmerman, J. Dodson, J. Linke, S. Lisgo, G. Pintsuk, S. Porro, et al., Thermal shock resistance of thick boron-doped diamond under extreme heat loads, Nucl. Fusion 51 (2011) 52001. doi:10.1088/0029-5515/51/5/052001.

[40] W.A.J. Vijvers, C.A.J. Van Gils, W.J. Goedheer, H.J. Van Der Meiden, D.C. Schram, V.P. Veremiyenko, et al., Optimization of the output and efficiency of a high power cascaded arc hydrogen plasma source, Phys. Plasmas 15 (2008) 93507. doi:10.1063/1.2979703.

[41] H.J. van der Meiden, R.S. Al, C.J. Barth, a J.H. Donné, R. Engeln, W.J. Goedheer, et al., High sensitivity imaging Thomson scattering for low temperature plasma., Rev. Sci. Instrum. 79 (2008) 13505. doi:10.1063/1.2832333.

[42] G.A. van Swaaij, K. Bystrov, D. Borodin, A. Kirschner, L.B. van der Vegt, G.J. van Rooij, et al., Dissociative recombination and electron-impact de-excitation in $\mathrm{CH}$ photon emission 
under ITER divertor-relevant plasma conditions, Plasma Phys. Control. Fusion 54 (2012) 95013. doi:10.1088/0741-3335/54/9/095013.

[43] J. Roth, Chemical erosion of carbon based materials in fusion devices, J. Nucl. Mater. 266 (1999) 51-57. doi:10.1016/S0022-3115(98)00658-8.

[44] S. Brezinsek, A. Pospieszczyk, A. Kirschner, G. Sergienko, A. Huber, V. Philipps, et al., Chemical Erosion Measurements in Tokamaks by Spectroscopy, Phys. Scr. 2004 (2004) 42. doi:10.1238/Physica.Topical.111a00042.

[45] J. Westerhout, N.J. Lopes Cardozo, J. Rapp, G.J. Van Rooij, CH spectroscopy for carbon chemical erosion analysis in high density low temperature hydrogen plasma, Appl. Phys. Lett. 95 (2009) 151501. doi:10.1063/1.3238295.

[46] J. Westerhout, D. Borodin, S. Brezinsek, N.J.L. Cardozo, J. Rapp, D.C. Schram, et al., The breakup of methane under ITER divertor hydrogen plasma conditions for carbon chemical erosion analysis with CH spectroscopy, Nucl. Fusion 50 (2010) 95003.

[47] P.D. Haaland, A. Garscadden, B. Ganguly, S. Ibrani, J. Williams, On form and flow in dusty plasmas, Plasma Sources Sci. Technol. 3 (1994) 381-387. doi:10.1088/09630252/3/3/022.

[48] A. Garscadden, B.N. Ganguly, P.D. Haaland, J. Williams, Overview of growth and behaviour of clusters and particles in plasmas, Plasma Sources Sci. Technol. 3 (1999) 239245. doi:10.1088/0963-0252/3/3/001.

[49] S. Mori, T. Ueno, M. Suzuki, Synthesis of carbon nanowalls by plasma-enhanced chemical vapor deposition in a CO/H2 microwave discharge system, Diam. Relat. Mater. 20 (2011) 1129-1132. doi:10.1016/j.diamond.2011.06.021.

[50] T.A. Witten, L.M. Sander, Diffusion-limited aggregation, Phys. Rev. B 27 (1983) 56865697. doi:10.1103/PhysRevB.27.5686.

[51] F.M.J.H. van de Wetering, J. Beckers, G.M.W. Kroesen, Anion dynamics in the first 10 milliseconds of an argon-acetylene radio-frequency plasma, J. Phys. D. Appl. Phys. 45 (2012) 485205. doi:10.1088/0022-3727/45/48/485205.

[52] J.J. Beulens, M. Buuron, D.C. Schram, Carbon deposition using an expanding cascaded arc d.c. plasma, 47 (1991) 401-417. doi:10.1016/0257-8972(91)90306-H.

[53] C. Jäger, T. Henning, R. Schlögl, O. Spillecke, Spectral properties of carbon black, J. Non. Cryst. Solids 258 (1999) 161-179. doi:10.1016/S0022-3093(99)00436-6. 
[54] J.F. Moulder, W.F. Stickle, P.E. Sobol, K.D. Bomben, Handbook of X-ray Photoelectron Spectroscopy, Perkin-Elmer Corporation Physical Electronics Division, Minnesota, 1992. doi:10.1002/sia.740030412.

[55] J. Robertson, Diamond-like amorphous carbon, Mater. Sci. Eng. R Reports 37 (2002) 129281. doi:10.1016/S0927-796X(02)00005-0.

[56] S. V. Singh, T. Zaharia, M. Creatore, R. Groenen, K. Van Hege, M.C.M. Van De Sanden, Hard graphitelike hydrogenated amorphous carbon grown at high rates by a remote plasma, J. Appl. Phys. 107 (2010) 13305. doi:10.1063/1.3273412.

[57] E. Vietzke, K. Flaskamp, V. Philipps, G. Esser, P. Wienhold, J. Winter, Chemical erosion of amorphous hydrogenated carbon films by atomic and energetic hydrogen, J. Nucl. Mater. 145-147 (1987) 443-447. doi:10.1016/0022-3115(87)90378-3.

[58] W. Jacob, J. Roth, Chemical sputtering, Top. Appl. Phys. 110 (2007) 329-400. doi:10.1007/978-3-540-44502-9-6.

[59] M. Hiramatsu, M. Hori, Carbon nanowalls: Synthesis and emerging applications, Springer Science \& Business Media, New York, 2010. doi:10.1007/978-3-211-99718-5.

[60] A. Ferrari, J. Robertson, Interpretation of Raman spectra of disordered and amorphous carbon, Phys. Rev. B 61 (2000) 14095-14107. doi:10.1103/PhysRevB.61.14095.

[61] S. Kurita, A. Yoshimura, H. Kawamoto, T. Uchida, K. Kojima, M. Tachibana, et al., Raman spectra of carbon nanowalls grown by plasma-enhanced chemical vapor deposition, J. Appl. Phys. 97 (2005) 104320. doi:10.1063/1.1900297.

[62] A.J.M. Buuron, J.J. Beulens, P. Groot, J. Bakker, D.C. Schram, Plasma deposited carbon films as a possible means for divertor repair, Thin Solid Films 212 (1992) 282-296. doi:10.1016/0040-6090(92)90534-I.

[63] J.M.D. Tascón, Novel carbon adsorbents, Elsevier, Oxford, 2012.

[64] M. Thommes, K. Kaneko, A. V Neimark, J.P. Olivier, F. Rodriguez-Reinoso, J. Rouquerol, et al., Physisorption of gases, with special reference to the evaluation of surface area and pore size distribution (IUPAC Technical Report), Pure Appl. Chem. 87 (2015) 1051-1069. doi:10.1515/pac-2014-1117.

[65] J.W.F. To, Z. Chen, H. Yao, J. He, K. Kim, H.-H. Chou, et al., Ultrahigh Surface Area Three-Dimensional Porous Graphitic Carbon from Conjugated Polymeric Molecular Framework, ACS Cent. Sci. 1 (2015) 68-76. doi:10.1021/acscentsci.5b00149. 
[66] V.A. Krivchenko, S.A. Evlashin, K. V Mironovich, N.I. Verbitskiy, A. Nefedov, C. Wöll, et al., Carbon nanowalls: the next step for physical manifestation of the black body coating., Sci. Rep. 3 (2013) 3328. doi:10.1038/srep03328.

[67] R.A. Felice, The spectropyrometer-a practical multi-wavelength pyrometer, Temp. Its Meas. Control Sci. Ind. Vol. 7, Part 2684 (2003) 711-716. doi:10.1063/1.1627211.

[68] J. Roth, R. Preuss, W. Bohmeyer, S. Brezinsek, A. Cambe, E. Casarotto, et al., Flux dependence of carbon chemical erosion by deuterium ions, Nucl. Fusion 44 (2004) L21L25. doi:DOI 10.1088/0029-5515/44/11/L01.

[69] B. V. Mech, A.A. Haasz, J.W. Davis, Isotopic effects in hydrocarbon formation due to lowenergy H+/D+ impact on graphite, J. Nucl. Mater. 255 (1998) 153-164. doi:10.1016/S00223115(98)00035-X.

[70] A. Bouchoule, Dusty Plasmas: Physics, Chemistry, and Technological Impact in Plasma Processing, Wiley, New York, 1999.

[71] K. De Bleecker, A. Bogaerts, W. Goedheer, Detailed modeling of hydrocarbon nanoparticle nucleation in acetylene discharges, Phys. Rev. E - Stat. Nonlinear, Soft Matter Phys. 73 (2006) 1-16. doi:10.1103/PhysRevE.73.026405.

[72] K. Hassouni, F. Mohasseb, F. Bénédic, G. Lombardi, A. Gicquel, Formation of soot particles in $\mathrm{Ar} / \mathrm{H} 2 / \mathrm{CH} 4$ microwave discharges during nanocrystalline diamond deposition: A modeling approach, Pure Appl. Chem 78 (2006) 1127-1145. doi:10.1351/pac200678061127.

[73] T. Matsoukas, M. Russell, Particle charging in low-pressure plasmas, J. Appl. Phys. 77 (1995) 4285-4292. doi:10.1063/1.359451.

[74] K. Ostrikov, E.C. Neyts, M. Meyyappan, Plasma Nanoscience: from Nano-Solids in Plasmas to Nano-Plasmas in Solids, Adv. Phys. 62 (2013) 113-224. doi:10.1080/00018732.2013.808047. 